IZA DP No. 8973

Market Design and Moral Behavior

Michael Kirchler Jürgen Huber Matthias Stefan Matthias Sutter

April 2015 


\title{
Market Design and Moral Behavior
}

\author{
Michael Kirchler \\ University of Innsbruck \\ Jürgen Huber \\ University of Innsbruck \\ Matthias Stefan \\ University of Innsbruck \\ Matthias Sutter \\ University of Cologne, University of Innsbruck and IZA
}

\author{
Discussion Paper No. 8973 \\ April 2015
}

IZA
P.O. Box 7240
53072 Bonn
Germany

\author{
Phone: +49-228-3894-0 \\ Fax: +49-228-3894-180 \\ E-mail: iza@iza.org
}

\begin{abstract}
Any opinions expressed here are those of the author(s) and not those of IZA. Research published in this series may include views on policy, but the institute itself takes no institutional policy positions. The IZA research network is committed to the IZA Guiding Principles of Research Integrity.

The Institute for the Study of Labor (IZA) in Bonn is a local and virtual international research center and a place of communication between science, politics and business. IZA is an independent nonprofit organization supported by Deutsche Post Foundation. The center is associated with the University of Bonn and offers a stimulating research environment through its international network, workshops and conferences, data service, project support, research visits and doctoral program. IZA engages in (i) original and internationally competitive research in all fields of labor economics, (ii) development of policy concepts, and (iii) dissemination of research results and concepts to the interested public.
\end{abstract}

IZA Discussion Papers often represent preliminary work and are circulated to encourage discussion. Citation of such a paper should account for its provisional character. A revised version may be available directly from the author. 


\section{ABSTRACT}

\section{Market Design and Moral Behavior}

In an experiment with 739 subjects we study whether and how different interventions might have an influence on the degree of moral behavior when subjects make decisions that can generate negative externalities on uninvolved parties. Particularly, subjects can either take money for themselves or donate it to UNICEF for measles vaccines. By considering two fairly different institutional regimes - one with individual decision making, one with a doubleauction market - we expose the different interventions to a kind of robustness check. We find that the threat of monetary punishment promotes moral behavior in both regimes. Getting subjects more involved with the traded good has no effect, though, in both regimes. Only the removal of anonymity, thus making subjects identifiable, has different effects across regimes, which we explain by different perceptions of responsibility.

JEL Classification: C91, C92, D47

Keywords: morals, market design, experiment

Corresponding author:

Matthias Sutter

University of Cologne

Department of Economics

Albertus-Magnus-Platz

50923 Cologne

Germany

E-mail: matthias.sutter@uni-koeln.de

\footnotetext{
* We thank Loukas Balafoutas, Anna Dreber Almenberg, Martin Dufwenberg, Armin Falk, Uri Gneezy, Martin Kocher, Thomas Stöckl, Nora Szech, three referees and seminar participants at the University of Cologne, University of Gothenburg and University of Innsbruck for valuable comments. We are particularly grateful to physician Dr. Herbert Bachler and want to acknowledge his participation in treatments CL PHYSICIAN and DA PHYSICIAN. Financial support from the Austrian Science Fund (FWF START-grant Y617-G11) and the Austrian Central Bank (Jubiläumsfonds grant 14953) is gratefully acknowledged. This study was approved by the Ethics Committee of the University of Innsbruck.
} 


\section{Introduction}

The question whether markets erode moral values is one of the most controversially discussed issues in philosophy and in the social sciences (Marx, 1904; Weber, 1978; Simmel, 1990; Shleifer, 2004; Sandel, 2012). Throughout history, the perception has swung back and forth between seeing markets as (i) civilizing and (ii) destructive. Proponents of the first view see markets as a civilizing force as they increase integrity, honest behavior, cooperation and trust among individuals. McCloskey (2006) argues that markets nurture "bourgeois virtues" and Friedman (1962) states that economic freedom is necessary for political freedom. The second view, that markets destruct moral values, strongly builds on the ideas of Marx (1904) about the alienation and exploitation of the workforce in the capitalist production process. Sandel (2012) argues that market norms might crowd out (pro-social) non-market norms and therefore a society should think carefully about the scope and limits of markets to allocate resources.

Pioneering experimental work by Falk and Szech (2013) has taken a big step to increase our understanding how markets may affect human behavior. They have investigated whether markets erode moral values by imposing negative externalities on uninvolved third parties. Falk and Szech (2013) have shown that experimental participants are more likely to accept the killing of a mouse in exchange for receiving a small monetary payment when participants interact on double-auction markets than when they make decisions individually, implying that people seem to act against their own moral standards when they engage in market interactions. Such evidence fuels the debate about the pros and cons of using markets for the allocation of goods. In particular, it raises the questions whether market design (Roth, 2002; Bolton and Ockenfels, 2012; Bartling and Weber, 2014) plays a crucial role for the degree of morality in markets and whether interventions to promote moral behavior in markets are possible. This paper addresses exactly these two questions.

In an experiment with 739 participants we study, first, how four different interventions affect moral behavior, and, second, how different institutional 
regimes interact with the different interventions ${ }^{1}$, thereby addressing the issue how robust the various interventions are. The first regime has its analogy in everyday consumption decisions, where individuals are price takers. Subjects decide about receiving a monetary payment (which mimics the utility gain from buying a good) at the cost of creating a negative externality to an uninvolved third party outside the laboratory in a choice list setting. If they refuse the monetary payment they can avoid the negative externality. The second regime is a double-auction market. It is motivated by financial markets where individuals trade with each other and where trading can create negative externalities on uninvolved third parties.

In both regimes subjects can choose between taking money for themselves or donating a potentially larger sum of money to UNICEF for measles vaccines. Measles are even nowadays taking a considerable death toll per year, with about 150,000 people estimated to die each year from measles infection, mostly children under the age of five. ${ }^{2}$ Hence, donating money to UNICEF is a potentially lifesaving act for a third party. We have consciously chosen this setting because presumably immoral behavior in our experiment involves negative consequences for people outside the laboratory. Refusing to donate for measles vaccine has potentially real-world consequences and does not only imply fairness concerns among participants inside the lab.

The experimental interventions that we test in both regimes are motivated by properties of markets that are most prominently considered to be the reason for (im)moral behavior: i) non-involvement with the traded good (Sandel, 2012), ii) anonymity of trading (Ariely et al., 2009), and iii) absence of punishment of a norm violation (Gintis et al., 2003; Fehr and Fischbacher, 2004). Holding the institutional regime constant, we examine whether (i) information campaigns to get traders involved with the traded good, (ii) removing anonymity of traders, or (iii) the opportunity to punish immoral traders affect moral behavior on markets. In addition, we test one technical intervention which only applies to

\footnotetext{
${ }^{1}$ Bartling and Weber (2014) have pointed out the relevance of market settings other than the double-auction market to consider moral behavior of subjects.

${ }^{2}$ WHO, http://www.who.int/mediacentre/factsheets/fs286/en/, February 2013.
} 
the double-auction regime. We investigate whether reminding traders of their responsibility during trading may avoid diluting responsibility on markets and hence make behavior more moral. We conjecture that the latter is specific to financial markets because traders' moral perception of what they trade might be easily diluted due to the technical and monetary characteristics of trading.

We find that interventions can affect moral behavior (i.e., the amount of money donated to UNICEF), but not all of them do. In both regimes, the potential threat of monetary punishment promotes more moral behavior, while in both regimes behavior does not change when subjects get more involved with the traded good through supplying detailed information on measles. Both types of interventions are robust to the regime under which they are implemented. Removing anonymity of trading has different effects across regimes, though. In fact, it only promotes more moral behavior in the choice list-regime, but not in the double-auction market. We try to explain this difference through different extents of diffusion of responsibility in both regimes. Finally, one treatment that is only implemented in the double-auction regime - reminding subjects of their responsibility before trading - does not affect moral behavior. In a post-experimental questionnaire, we show that donating money to UNICEF is, indeed, what subjects consider as the moral action that ought to be taken in our experiment.

\section{The Experiment}

\subsection{Design of Baseline-Treatments}

In the first regime subjects act in a choice list framework. This regime has its analogy in everyday consumption choices with possible negative externalities (e.g., child labor or inhumane working conditions). Individuals do not bargain with others, but are price takers. They can either take a monetary payment (which mimics the utility gain from consumption) or make a donation to UNICEF for measles vaccine. Taking the money creates a negative externality of no donation to UNICEF (which could have saved human lifes) while 
refusing the money avoids such a negative externality. Because subjects make such decisions for a variety of different amounts of money to be taken instead of donating a fixed amount (see below for details), we call this regime the choice list-regime, abbreviated as CL.

The second regime is implemented as a double-auction market, abbreviated as DA. Subjects bargain over splitting an amount of money between themselves or donating to UNICEF for measles vaccine. The analogy for this regime comes from financial markets like soft commodity markets. Here traders set prices of goods which can have negative externalities for third parties - e.g., potential speculative price increases in food markets for rice or wheat which are beneficial for investors, but might harm the poor outside the financial market.

Participants in treatments of regime CL are facing a list of 22 choices between a payment to themselves ranging from 0.40 Euro to 21.40 Euro (increasing in steps of one Euro) and the donation of 10.70 Euro to UNICEF in each of 10 periods. The amount donated to UNICEF is worth half a package with 100 doses of measles vaccine. The procedure of determining which choice pair is selected for payment is as follows. First, subjects have to make decisions in the price-list for 10 periods and then one period is chosen randomly, of which again one of the 22 choice pairs is selected randomly for payment. We let subjects repeat the price-list ten times to keep conditions similar to the treatments in Falk and Szech (2013). Furthermore, in the treatments with interventions outlined below the repetition of the price-list procedure allows for learning from feedback after each period. Therefore, to compare these interventions treatments to the baseline treatment, we keep the conditions identical. The baseline treatment in regime CL, as described here, is called CL_BASE.

Participants in treatments of regime DA trade in a double-auction market where they can post limit orders and accept them by posting market orders. To mimic the multilateral markets of Falk and Szech (2013) as closely as possible, we implement a market surplus of two sellers by assigning six subjects as sellers and four subjects as buyers. Each seller holds one package with 100 doses of measles vaccine. For every seller that does not trade, these 100 units of measles vaccine 
are donated to UNICEF for 21.40 Euro. If, however, a seller and a buyer agree on a price $\mathrm{P}$, the seller receives $\mathrm{P}$ as payoff, and the buyer gets 21.40 Euro minus P. In this case there is no donation. The market runs for ten trading periods of three minutes each. Orders are executed according to price and then time priority. Market orders have priority over limit orders and are always executed instantaneously. The trading screen provides real-time information about the current price in a chart and about the number of transactions in the period (see the instructions in the Appendix). Once a subject traded in a market, her remaining open limit orders are removed from the order book, as each subject can conclude only one trade per period. At the end of the experiment one period is drawn randomly and is implemented with all monetary consequences. The baseline double-auction market treatment is labelled DA_BASE.

\subsection{Design of Treatments with Interventions and Their Motivation}

Treatments CL_PHYSICIAN and DA_PHYSICIAN are identical to the respective baseline treatments, but before trading starts a physician who works for "Doctors Without Borders" (Médecins Sans Frontières - MSF) gives a tenminutes presentation on measles and measles vaccination. This presentation provides subjects with detailed information on the effects of measles, such as death tolls and possible prevention, and how the vaccination works. The slides of the presentation and the script of the physician are intended to get subjects more strongly involved with the traded good (the vaccine) - see sections 5.5 and 5.6 in the Appendix. This intervention has its analogy in the real world in the use of information campaigns that should increase subjects' involvement with an issue and should change behavior by educating people. We conjecture similar effects of this intervention in both regimes.

Treatments CL_IDENTIFIABILITY and DA_IDENTIFIABILITY are identical to the respective baseline treatments with the sole difference that anonymity is removed in the following way. After each period in CL_IDENTIFIABILITY all subjects in a session are informed about whether the other subjects have 
taken money for themselves or donated to UNICEF in the randomly selected choice pair of the previous period. Subjects can be identified by seat number, but not by name. Subjects also get a history of all periods up to the current one. Similarly, after each period all subjects in DA_IDENTIFIABILITY are informed about whether and how often a particular subject has taken money (through a trade) or donated to UNICEF (by refusing to trade) in the previous period and throughout all periods. Again, identification is possible by a subject's seat number only. Before the final questionnaire of the experiment is administered, subjects in both treatments are called to the front desk in public to receive payment in order of their seat number. Thereby, each participant can identify how often a subject took money for herself instead of donating it and so strict anonymity is removed. This procedure was announced in detail at the beginning of the experiment. We conjecture a stronger effect in CL_IDENTIFIABILITY as diffusion of responsibility is not possible here. Whereas subjects are solely responsible for their actions in CL_IDENTIFIABILITY, there is always a counterpart to trade in DA_IDENTIFIABILITY which leads to a diffusion of responsibility in double-auction markets. Each trading partner can always excuse herself by arguing that without the second party's agreement she would not have traded and thus not have obstructed the donation. Such a line of reasoning is impossible in CL_IDENTIFIABILITY. Therefore we expect that being solely identifiable for immoral actions by the public is more strongly avoided by the subjects in regime CL. Both treatments are related to and motivated by a field setting in which, e.g., NGOs use lists of socially irresponsible companies to identify them for a broader public, i.e., for so called "name and shame" campaigns. ${ }^{3}$

Treatments CL_PUNISHMENT and DA_PUNISHMENT are identical to the respective baseline treatments with the exception that two additional subjects act in each cohort/market as observers. Although observers are not materially affected by the actions chosen by the others, they can punish behavior if they wish. Each observer is endowed with 21.40 Euro per period and is linked to

\footnotetext{
${ }^{3}$ We test the impact of this intervention in a single shot environment where we cannot control for reputation concerns. If we find effects in a one shot setting, it is likely to find even stronger effects in a repeated setting.
} 
five other participants in CL_PUNISHMENT or to three sellers and two buyers in DA_PUNISHMENT throughout the entire experiment. After each period an observer in CL_PUNISHMENT gets informed about the choice pair at which a particular subject switched from donating to taking the individual payment, which choice pair was chosen and would be paid if the previous period were randomly selected for actual payment. Furthermore each observer also gets the information how often an assigned subject took money for herself (or refused to do so) in all periods so far. ${ }^{4}$ In treatment DA_PUNISHMENT observers can watch the market during trading and so they observe trading activity, such as posted limit orders and market prices. At the end of each period an observer receives information about which of his assigned subjects traded in the last period. Furthermore an observer also receives information how often the assigned subjects traded - or did not trade - in all periods so far. This identification in both treatments is done by a subject-ID which is not identical to a subject's seat number, though. Each observer can assign up to three Euro of his endowment per period to each of the five assigned participants. For each Euro spent on punishment by the observer, a particular subject loses three Euro. Therefore, punishment is costly for the observer, but even more so for the punished subject. We would like to note that punishment is designed to be as similar as possible across regimes. ${ }^{5}$ To mimic the observation of trading prices in the double auction regime, we display the choice pair at which subjects switch to the individual payout in the choice list regime. Hence, we expect similar effects of punishment in both regimes. Analogies in the field to our treatments with a punishment opportunity would be costly NGO actions against norm violations or law enforcements by governments.

In addition to the above described treatments we run one more double-

\footnotetext{
${ }^{4} \mathrm{We}$ also ran an alternative version of the punishment treatment, called CL_PUNISHMENT_MILD. Here, we tested the impact of a "mild" version of punishment as the observers received little information on the subjects' actions. The observers only got information whether a donation was made in the previous period and how often money was donated up to the current period by each subject. Subjects' decisions for each single choice pair were not disclosed. Results are reported in the Appendix.

${ }^{5}$ We would like to thank an anonymous referee for suggesting treatment CL_PUNISHMENT as a more suitable comparison treatment to DA_PUNISHMENT than the original treatment CL_PUNISHMENT_MILD was.
} 
auction treatment which is much less reasonable to test in the CL-framework. Treatment DA_RESPONSIBILITY is identical to DA_BASE, with the only difference that every time a limit or a market order is posted a pop-up appears, reminding subjects that trading may have the effect that no donation will be made. The pop-up window for market orders reads as follows: "If you do trade, NO donation for the measles vaccine can be made on your behalf for this period. Do you want to continue?" The pop-up window for limit orders reads as follows: "If you post an offer, this can lead to a trade. In the latter case NO donation for the measles vaccine can be made on your behalf for this period. Do you want to continue?" This treatment is intended to test whether reminding traders of their responsibility may avoid a loss of focus on the moral dimension of trading and the dilution of responsibility on double-auction markets and hence make behavior more moral. This intervention is relevant for trading on financial markets because in this environment traders might lose attention about what they trade due to the technical and monetary characteristics of trading. By drawing their focus on the moral and normative dimension of the traded good, they might change their behavior accordingly (Krupka and Weber, 2009).

\subsection{Experimental Procedure}

In the CL-regime, 60 subjects participated in each treatment, except in CL_PUNISHMENT where 72 subjects were tested (60 decision makers and 12 observers). These sessions were run in May and in October 2014, yielding one independent observation per participant. In the DA-regime, we conducted eight markets (as independent observations) with ten subjects each in each treatment, except for DA_PUNISHMENT with eight markets of twelve subjects (ten market traders and two observers) each. These sessions were run from May to July $2013 .{ }^{6}$ In total, 739 bachelor and master students participated in the experiment. ${ }^{7}$ Each

\footnotetext{
${ }^{6}$ Initially, we had also run CL_BASE in early 2013. Yet, when extending the CL-regime upon the useful suggestions of a referee, we decided to re-run CL_BASE again in May 2014 to keep the conditions (in particular the time of execution) within the CL-regime identical. It is reassuring to note that the data for CL_BASE which are presented in the following are not significantly different from those in 2013 which we do not report here (Wilcoxon signed-ranks test, $p=0.164, N=108)$.

${ }^{7}$ In one session of treatment DA_PHYSICIAN we tested only 19 instead of 20 participants since subjects (in all treatments) were free to leave it they felt to have a moral conflict.
} 
subject participated in only one session of this study and the show-up fee was 10 Euro. $^{8}$ All sessions were run at Innsbruck EconLab at the University of Innsbruck.

In total, each experimental session lasted between 60 and 90 minutes. At the beginning of each session subjects had 15 minutes to read the instructions on their own and subjects' questions were answered privately. Then the trading or choice list screen was explained, followed by a non-incentivized trial period of three minutes to become familiar with the interface.

After subjects had read the instructions they had the possibility to leave the experiment if they felt to have a moral conflict in participating. Subjects that chose to leave the experiment received the show-up fee of 10 Euro and were replaced with reserve candidates. The latter were assigned the roles of reserves and were present from the beginning of the experiment. In sum, 34 participants left the sessions, with all except one being replaced by reserve candidates. There are no significant differences across treatments in the number of subjects leaving.

At the end of the ten trading periods, subjects had to answer a questionnaire on their current emotional state. Participants also answered a questionnaire with several demographic questions and questions about their moral judgement of trading. Subjects received the payment in private and anonymously by another researcher who was not in the room during the experiment. The experiments were programmed and conducted with z-Tree 3.3.6 by Fischbacher (2007). Subjects were recruited using ORSEE by Greiner (2004) and HROOT by Bock et al. (2012).

\footnotetext{
In this particular session of DA_PHYSICIAN more participants chose to leave than reserve participants attended.

${ }^{8}$ The show-up fee was chosen to be rather high to ensure that subjects would receive at least an amount of money in the experiment that is comparable to other experiments run in Innsbruck irrespective of their donation behavior. Furthermore, subjects were told that they will receive a receipt about the amount donated in the sessions two months after the experiment, which was actually done. The total amount of money donated to UNICEF was 3445.40 Euros, allowing for 16,100 measles vaccinations.
} 


\section{Results}

\subsection{Descriptive Overview}

Figure 1 shows descriptive results for the CL-treatments. In the top panel we show the average amount in Euro at which subjects switch from donating to UNICEF (which they did for lower amounts) to taking the individual payment (for amounts at the average or higher). We observe that the average subject in CL_BASE already prefers 9.40 Euro for herself over donating to UNICEF. The average amount for switching is larger in the other CL-treatments, reaching around 11.40 Euro in CL_PUNISHMENT. The bottom panel of Figure 1 shows the development of switching points (translated into the respective amount of Euros for the subject) over time for each treatment. We observe slightly negative time trends in most treatments, most pronounced in CL_PUNISHMENT. 

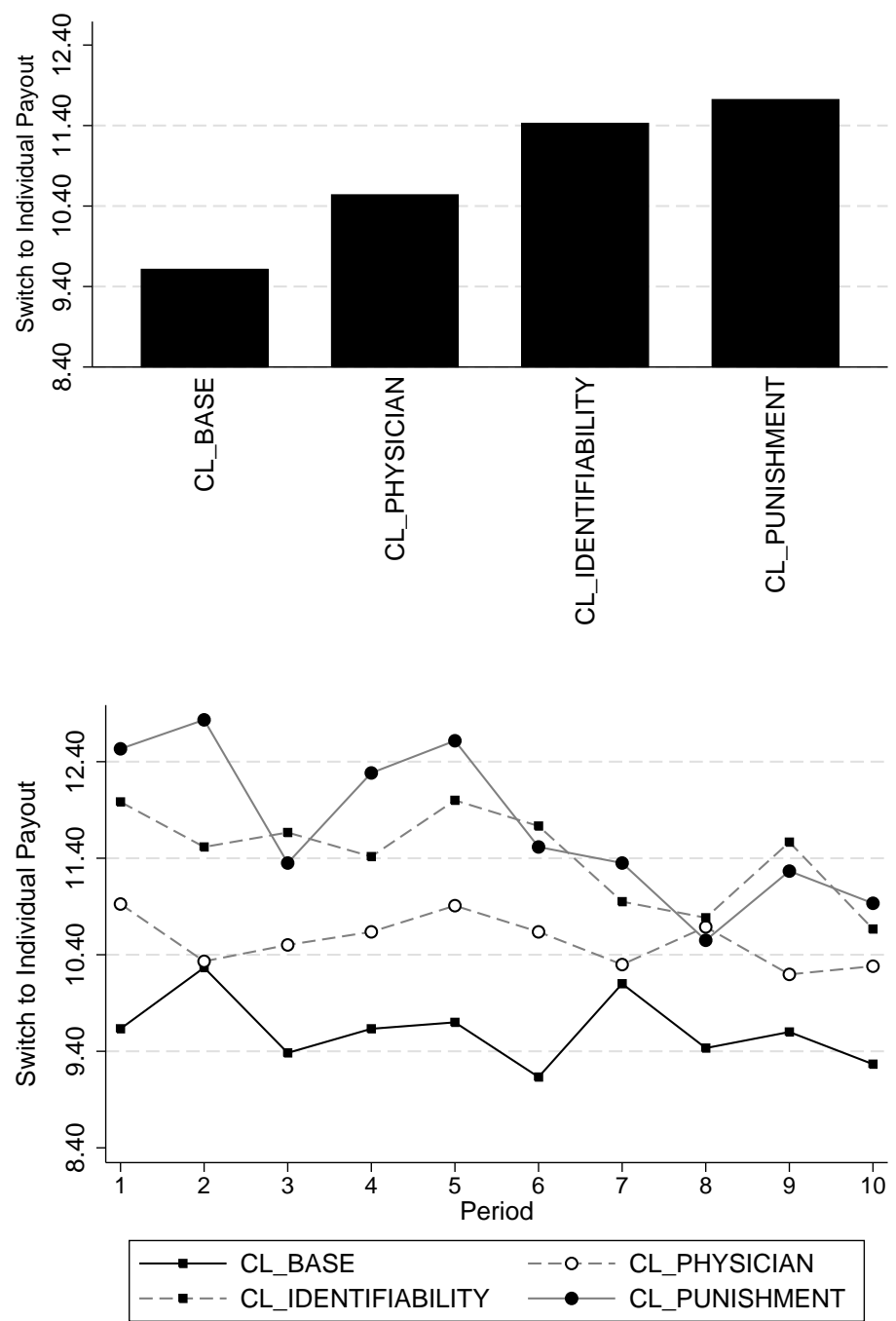

Figure 1: TOP: Average amount of money where subjects switch from donating money to UNICEF to taking the money for themselves. BOTTOM: Average amount of money where subjects switch over time. 
Figure 2 shows descriptive results for the DA-treatments. In the top panel we normalize the absolute number of trades by the maximum number of possible trades, i.e., by the number of buyers in the market. We observe that three intervention treatments - DA_RESPONSIBILITY, DA_PHYSICIAN, and DA_IDENTIFIABILITY - are practically at par with DA_BASE. In fact, those four treatments are all in a very narrow range from 82 percent to 84 percent. Only when the possibility of monetary sanctions through observers is introduced in DA_PUNISHMENT, the relative frequency of trade drops markedly to 69 percent. 

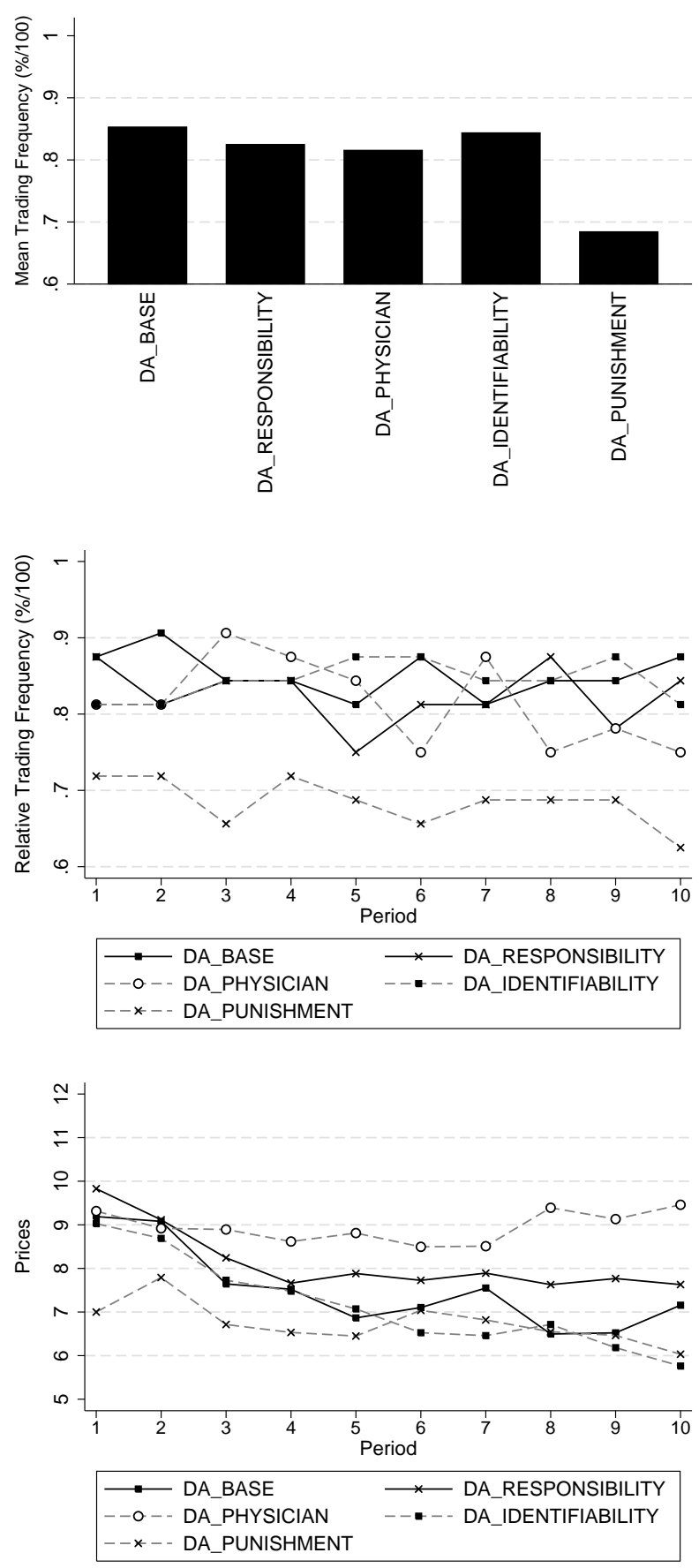

Figure 2: TOP: Average trading frequency in each treatment of regime DA. MIDDLE: Average trading frequency over time. BOTTOM: Mean prices over time. 
The middle panel of Figure 2 shows the development of the relative trading frequency over time for each treatment, indicating no clear time trends. The bottom panel of Figure 2 presents the mean trading prices over time across all markets in a particular treatment. Identical to Falk and Szech (2013), we observe that prices decline over time in all treatments, except in DA_PHYSICIAN.

\subsection{Statistical Tests}

To test for statistical differences between the treatments of regime CL we run GLS random effects panel regressions with 239 cross-sections $s$ (subjects) and 10 observations over time $p$ (periods). To account for correlation across periods we apply clustered standard errors on a cohort level of 10 subjects (White, 1980). ${ }^{9}$ In Table 1 the number of the choice pair where subject $i$ switches from making a donation to preferring the individual payment (SWITCHING POINT) serves as dependent variable. ${ }^{10}$ In Model (1) we use binary treatment dummy variables as predictor variables. Treatment CL_BASE serves as benchmark and is captured with the intercept $\alpha$. In Model (2) we additionally investigate the time trend in each treatment by adding a variable PERIOD that runs from 1 to 10 and indicates the time trend of CL_BASE. The interaction of PERIOD with the different treatments measures the differences in time trends with respect to CL_BASE.

We find that subjects switch from the donation to the individual payment at significantly higher individual payments in treatments CL_IDENTIFIABILITY and CL_PUNISHMENT, compared to the baseline CL_BASE. Furthermore, we find no time trend in the baseline treatment and no differences in time trends except for treatment CL_PUNISHMENT. It is important to mention that the coefficients of CL_IDENTIFIABILITY and CL_PUNISHMENT remain

\footnotetext{
${ }^{9}$ In treatment CL_IDENTIFIABILITY a cohort of 10 subjects is connected by seeing each other's decisions and in treatment CL_PUNISHMENT a cohort of 10 subjects is connected by two observers, who see their decisions and can punish them. Therefore, we take into account possible correlations between these subjects. For consistency reasons we applied clustered standard errors for all CL-treatments alike, including CL_BASE.

${ }^{10}$ Since the dependent variable is integer and discrete, one should use a GLS random effects panel regression cautiously. For this reason, we additionally conducted Ordered Probit as well as Negative Binomial regressions for Model (1). We find the same treatments to be significant in both regressions compared to the GLS random effects regression as shown in Table 1 . The two additional regressions are reported in Table A3 in the Appendix.
} 
Table 1: GLS random effects panel regression for subjects' switching from the donation to the individual payment in the individual treatments.

\begin{tabular}{lcc}
\hline \hline & $\begin{array}{c}\text { SWITCHING POINT } \\
\text { Model }(1)\end{array}$ & $\begin{array}{c}\text { SWITCHING POINT } \\
\text { Model }(2)\end{array}$ \\
\hline CL_PHYSICIAN & 0.926 & 0.933 \\
& $(1.171)$ & $(1.275)$ \\
CL_IDENTIFIABILITY & $1.813^{* *}$ & $2.170^{* * *}$ \\
& $(2.128)$ & $(2.701)$ \\
CL_PUNISHMENT & $2.108^{* *}$ & $2.988^{* * *}$ \\
& $(2.279)$ & $(3.557)$ \\
PERIOD & & -0.042 \\
& & $(-0.785)$ \\
PERIOD*CL_PHYSICIAN & & -0.001 \\
& & $(-0.019)$ \\
PERIOD*CL_IDENTIFIABILITY & & -0.065 \\
& & $(-0.924)$ \\
PERIOD*CL_PUNISHMENT & & $-0.160^{* *}$ \\
& & $(-2.373)$ \\
$\alpha$ & $(13.969)$ & $9.444^{* * *}$ \\
& $(2390$ & $(17.525)$ \\
$p$-value of $F$-test & 0.073 & 0.000 \\
\hline \hline
\end{tabular}

Dependent variable: number of the choice pair where subject $i$ switches from donating to UNICEF to preferring the individual payment (SWITCHING POINT). The variable ranges from 0 (the subject always takes the individual payment) to 22 (the subject always donates). Binary dummy variables for each treatment serve as independent variables. Treatment CL_BASE is the benchmark and is therefore captured with the intercept $\alpha$. Standard errors on a cohort level (i.e., the cohort of subjects that constitute an experiment session) are clustered to account for correlations between subjects. $z$-values are given in parentheses.

$*, * *$ and ${ }^{* * *}$ represent the $10 \%, 5 \%$ and the $1 \%$ significance levels of a two-sided test.

significant in model (2). This means that the effect of removing anonymity and the threat of monetary punishment is already present at the beginning of the experiment and that both interventions have an effect even before subjects start observing the actions of others or can be punished. ${ }^{11}$

To test for statistical differences between the treatments of regime DA we run a similar GLS random effects panel regressions with clustered standard errors on a session level (White, 1980). In Table 2 the relative frequency of

\footnotetext{
${ }^{11}$ Table A1 in the Appendix gives pairwise coefficient tests of the explanatory variables of Table 1. None of the tests is significant.
} 
trade (TRADE) - i.e., the number of trades as a ratio of the maximum possible number of trades in period $p$ of market $m$ - and the respective average trading price (PRICE) serve as dependent variables. 
Table 2: GLS random effects panel regression for relative trading frequency and market prices in the market treatments.

\begin{tabular}{|c|c|c|c|c|}
\hline & $\begin{array}{c}\text { TRADE } \\
\text { Model (1) }\end{array}$ & $\begin{array}{c}\text { TRADE } \\
\text { Model (2) }\end{array}$ & $\begin{array}{c}\text { PRICE } \\
\text { Model (1) }\end{array}$ & $\begin{array}{c}\text { PRICE } \\
\text { Model (2) }\end{array}$ \\
\hline DA_RESPONSIBILITY & $\begin{array}{c}-0.028 \\
(-0.323)\end{array}$ & $\begin{array}{c}-0.031 \\
(-0.364)\end{array}$ & $\begin{array}{c}0.535 \\
(0.474)\end{array}$ & $\begin{array}{c}0.406 \\
(0.464)\end{array}$ \\
\hline DA_PHYSICIAN & $\begin{array}{c}-0.038 \\
(-0.453)\end{array}$ & $\begin{array}{c}0.002 \\
(0.024)\end{array}$ & $\begin{array}{l}1.596 \\
(0.950)\end{array}$ & $\begin{array}{c}0.514 \\
(0.422)\end{array}$ \\
\hline DA_IDENTIFIABILITY & $\begin{array}{c}-0.009 \\
(-0.138)\end{array}$ & $\begin{array}{l}-0.040 \\
(-0.589)\end{array}$ & $\begin{array}{c}-0.385 \\
(-0.286)\end{array}$ & $\begin{array}{c}0.140 \\
(0.141)\end{array}$ \\
\hline DA_PUNISHMENT & $\begin{array}{l}-0.169^{* *} \\
(-2.430)\end{array}$ & $\begin{array}{l}-0.150^{* *} \\
(-1.963)\end{array}$ & $\begin{array}{c}-0.776 \\
(-0.545)\end{array}$ & $\begin{array}{c}-1.473 \\
(-1.219)\end{array}$ \\
\hline PERIOD & & $\begin{array}{l}-0.003 \\
(-1.473)\end{array}$ & & $\begin{array}{l}-0.241^{* * *} \\
(-2.616)\end{array}$ \\
\hline PERIOD*DA_RESPONSIBILITY & & $\begin{array}{c}0.001 \\
(0.164)\end{array}$ & & $\begin{array}{c}0.023 \\
(0.215)\end{array}$ \\
\hline PERIOD*DA_PHYSICIAN & & $\begin{array}{c}-0.007 \\
(-1.284)\end{array}$ & & $\begin{array}{c}0.197 \\
(1.483)\end{array}$ \\
\hline PERIOD*DA_IDENTIFIABILITY & & $\begin{array}{c}0.005 \\
(1.107)\end{array}$ & & $\begin{array}{c}-0.095 \\
(-0.738)\end{array}$ \\
\hline PERIOD*DA_PUNISHMENT & & $\begin{array}{c}-0.003 \\
(-0.543)\end{array}$ & & $\begin{array}{c}0.127 \\
(1.012)\end{array}$ \\
\hline$\alpha$ & $\begin{array}{c}0.853^{* * *} \\
(14.835)\end{array}$ & $\begin{array}{c}0.869^{* * *} \\
(16.030)\end{array}$ & $\begin{array}{l}7.410^{* * *} \\
(7.321)\end{array}$ & $\begin{array}{l}8.735^{* * *} \\
(10.850)\end{array}$ \\
\hline$N$ & 400 & 400 & 400 & 400 \\
\hline$p$-value of $F$-test & 0.024 & 0.010 & 0.566 & 0.000 \\
\hline
\end{tabular}

Dependent variables: relative trade frequency (TRADE) and mean market prices (PRICE). TRADE measures the number of trades as a ratio of the maximum possible number of trades in period $p$ of market $m$. Binary dummy variables for each treatment serve as independent variables. Treatment DA_BASE is the benchmark and is therefore captured with the intercept $\alpha$. Standard errors on a market level are clustered to account for correlations between subjects. $z$-values are given in parentheses.

$*, * *$ and $* * *$ represent the $10 \%, 5 \%$ and the $1 \%$ significance levels of a two-sided test. 
We find that the relative trading frequency is only significantly reduced in treatment DA_PUNISHMENT compared to DA_BASE (see column 1). We further find that there are no differences in time trends between DA_BASE and the other treatments with respect to the trading frequency. Again, it is important to mention that the coefficient of the treatment dummy of DA_PUNISHMENT remains significant in model (2). This indicates a significantly lower trading frequency already in period 1 before any monetary punishment is possible. This is evidence for the effect that already the threat of potential punishment increases moral behavior on markets in treatment DA_PUNISHMENT.

In the two right-most columns we show that price levels are indifferent between treatments. In addition, we find the typical negative price trend of treatment DA_BASE - as also found in Falk and Szech (2013) - but no treatment differences with respect to the time trend. ${ }^{12}$

We can summarize the two major results of our experiment as follows:

Result 1: In the CL-regime, removing participants' anonymity and the threat of punishment lead to more moral behavior. Increasing the involvement of participants, however, does not improve moral behavior.

Result 2: In the DA-regime, all non-monetary interventions - i.e., reminding participants of their responsibility, increasing the involvement of participants with the traded good, and removing participants' anonymity - fail to lead to more moral behavior. Only the threat of punishment improves moral behavior in this framework.

\subsection{Discussion of Results}

The findings of the previous subsection raise some important questions. The first one addresses why we do not provide statistical comparisons between regimes for the same intervention (treatment). We believe that making these comparisons in a controlled way is almost impossible as both regimes differ in more than just one dimension, which makes it very difficult to attribute particular treatment

\footnotetext{
${ }^{12}$ Table A2 in the Appendix gives pairwise coefficient tests of the explanatory variable TRADE of Table 2. We observe significantly fewer trades and hence more moral behavior in treatment DA_PUNISHMENT compared to all other treatments.
} 
differences to specific causes. Some of the most important differences between CL and DA are the following: individual decision making in CL vs. interactive decisions (on markets) in DA; no feedback during the decision process in CL vs. permanent feedback about prices and other subjects' offers in DA; relatively quick decisions in CL (by clicking through the 22 choice pairs) vs. three minutes of trading in each period in DA. Therefore, we abstain from directly comparing the same interventions across regimes. We would like to recall that the aim of having the two different regimes was to investigate how various interventions work in different environments - that share some features with respect to trading off money and a potentially life-saving donation, but that differ in many others. So, the two regimes are mainly motivated to check the robustness of interventions.

The second major question is why interventions in both regimes do not always yield identical results. Note first that the additional information provided by the physician, as well as the opportunity of monetary punishment, do lead to the same outcomes across regimes (with the physician having no effect, but the monetary punishment having one). This means that only the intervention of removing anonymity in treatments DA_IDENTIFIABILITY and CL_IDENTIFIABILITY has different effects across regimes. We conjecture that the following explanations might account for this difference. In the doubleauction markets subjects share responsibility as there is always a counterpart when trading occurs. In regime CL subjects do not share the responsibility of refusing to donate, but are solely responsible for their actions. This difference between regimes can likely be attributed to the diffusion of responsibility (Darley and Latane, 1968; Ciccarelli and White, 2009). In the choice list regime each subject determines the final outcome herself and there is no other subject that can be blamed for it. In the double-auction setting, in contrast, a trade can only be conducted when two subjects agree on it. Therefore, in this setting the actions of two subjects determine the final outcome, where each one can excuse herself by blaming the other for concluding the trade. Since such diffusion of responsibility does not exist in regime CL, being individually identifiable for immoral actions 
by the public might be more strongly avoided by the subjects in treatment CL_IDENTIFIABILITY than in treatment DA_IDENTIFIABILITY. Another reason why we don't observe an effect in DA_IDENTIFIABILITY might be that in this treatment subjects can immediately see when and that other subjects in the market trade. Given the high frequency of trading, observing others trade might create a perception that trading - and thus taking the money - is socially acceptable. In treatment CL_IDENTIFIABILITY it is less obvious that others take the money instead of donating, because that depends upon which choice is randomly selected for implementation. This difference might contribute to the different effects of identifiability across regimes. Of course, the two explanations offered here do not rule out other causes, but we need to leave this an open question for the future.

The third major question is concerned with the real-world analogy of our CL-treatments. Our choice-list regime is comparable to the individual treatment of Falk and Szech (2013). Although they interpret it as an individual decision frame and contrast it to double-auction markets, we believe that this individual decision making in the CL-regime resembles many everyday life situations of decisions in market settings as well. As customers, individuals are often price takers without an opportunity to bargain about prices. They decide about buying or not buying a product (often at varying prices), and in case of buying it they are obviously willing to accept the potential harm done to uninvolved third parties.

Fourth, previous work by Masclet et al. (2003) has found that non-monetary sanctions can make subjects more cooperative in the framework of public goods provision. They show that both monetary and non-monetary sanctions increase contributions to a public good initially, compared to a baseline condition without sanctions, but monetary sanctions lead to higher contributions than nonmonetary sanctions in the long run, and the effect of non-monetary sanctions decreases substantially over time. In our view, the pattern found in Masclet et al. (2003) need not contradict our findings that non-monetary interventions do not have an impact on moral behavior on markets. One major difference 
between the setting in Masclet et al. (2003) and ours is that the contributions to the public good are visible to all other group members before punishment is possible and executed by other group members in Masclet et al. (2003), while in our setting a subject's behavior cannot be identified by other market participants, but can only be observed by two observers. In other words, the Masclet et al. (2003) study relies on second-party punishment, while we rely on thirdparty punishment. Given that third-party punishment seems to have weaker effects than second-party punishment (Leibbrandt and López-Pérez, 2012), this difference might explain why we did not find significant effects of non-monetary interventions. Since monetary interventions did work, we are going to explore the behavior of observers in the treatments with punishment in more detail in the next subsection.

\subsection{Analysis of Observer Behavior}

Figure 3 shows the average amount of Euros spent for punishment per subject and period in CL_PUNISHMENT. We find that the amount used for punishment is low and on average amounts to 0.25 Euro per participant and period. To investigate whether there is a relationship between a subject's frequency of taking the payment for herself and the total amount of Euros she is punished with, we run GLS panel regressions (60 subjects, 10 observations over time each). We first normalize the amount of punishment on a specific subject by the total punishment that the respective observer implements on all five assigned subjects (thus controlling for individual differences across observers) and then regress this relative amount of punishment on the variable SWITCHING POINT, furthermore on a dummy variable indicating whether the subject received an individual payment in the last period (PAYOUT), and on a period variable (PERIOD). We cluster standard errors on a cohort level of 10 subjects each (White, 1980). ${ }^{13}$ We find a significantly negative coefficient for SWITCHING POINT and a significantly positive coefficient for PAYOUT. This indicates

\footnotetext{
${ }^{13}$ As mentioned above, for treatment CL_PUNISHMENT we have to take into account possible correlations within the cohort of ten subjects across periods. For consistency reasons we applied clustered standard errors for all CL-treatments alike.
} 
that observers punish subjects more severely when they have taken the individual payout already at lower amounts and when they have more often taken money in the past instead of donating to UNICEF. PERIOD is significantly negative, indicating that observers punish less over time. ${ }^{14}$

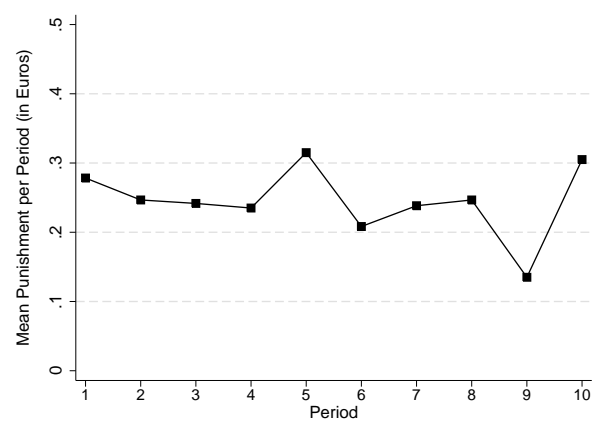

Figure 3: Average amount of Euro spent for punishment per subject and period in treatment CL_PUNISHMENT.

Across all markets in treatment DA_PUNISHMENT, 90.1 percent of all Euros spent for punishment are allocated to subjects who traded in the current period. Only 9.9 percent were spent on subjects who did not trade in the current period, but typically had traded in a previous period. On average, an observer spends 0.33 Euros on each market participant (irrespective of trading activity) in each period. The average deduction from subjects who traded in the current period is 1.61 Euros, and thus fairly small, compared to the potential gains from trade. The left panel of Figure 4 shows the average amount of Euros spent for punishment per market participant and period. We find that the amount used for punishment decreases over time to a value below 0.20 Euros in the last period. The right panel of Figure 4 shows the amount spent for punishment for sellers and buyers separately over time. We see that both roles are punished equally over time by the observers. We run an analogous GLS regression for regime DA as for CL. As explanatory variables we use a period variable (PERIOD) and a binary dummy variable (TRADING) indicating whether a subject traded in the last period. The coefficient for TRADING is significantly positive

\footnotetext{
${ }^{14}$ This regression is reported in Table A4 in the Appendix.
} 
indicating that less moral behavior is punished more frequently. ${ }^{15}$
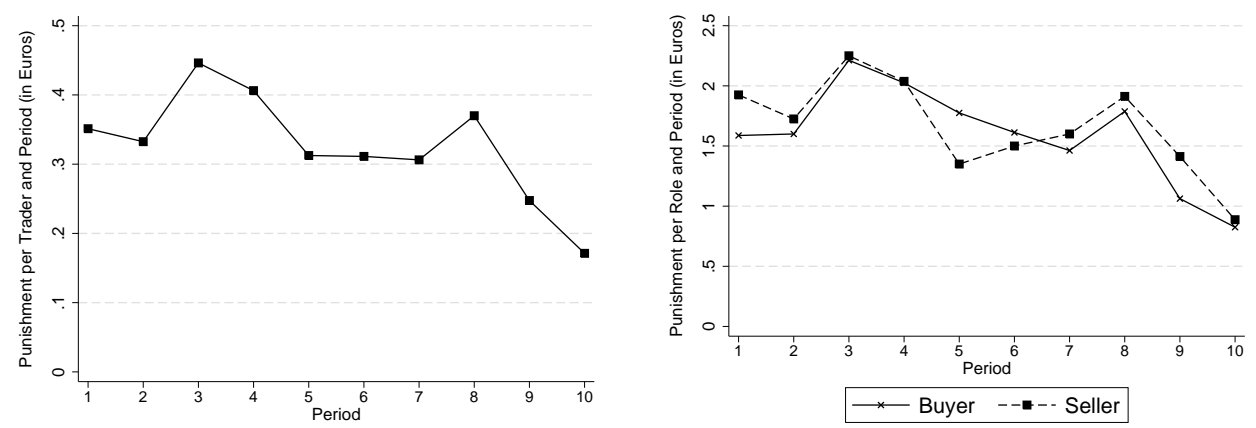

Figure 4: LEFT: Average amount of Euro spent for punishment per subject and period. RIGHT: Average amount of Euro spent for punishment over time, separated for sellers and buyers. Both panels show average values across all markets in treatment DA_PUNISHMENT.

Note that the results on punishment in CL_PUNISHMENT and DA_PUNISHMENT

suggest that the mere possibility of punishment has a positive effect on moral behavior in both regimes. As outlined in columns (2) of Tables 1 and 2 the differences in trading frequency between both punishment treatments and the corresponding base treatments are significant already in the first period when no prior punishment is possible.

\subsection{Final Questionnaire}

As a final, and important, point we examine whether trading or taking money individually in our experiment is, indeed, regarded as unethical. Post-experimental survey evidence from 115 participants in regime CL and from 255 participants in regime DA reveals that participants judge others who take money for themselves as significantly less moral than those who refrain from trading. ${ }^{16}$ The questionnaire was handed out at the end of the experiment, which had not been announced at the beginning of the experiment. The two questions on the assessment of the moral dimension of trading read as follows:

\footnotetext{
${ }^{15}$ This regression is reported in Table A5 in the Appendix.

${ }^{16}$ We only administered the questionnaire for three treatments of regime DA DA_PHYSICIAN, DA_IDENTIFIABILITY, and DA_PUNISHMENT - and, due to time constraints, not for sessions of treatment CL_PHYSICIAN and CL_PUNISHMENT, but only for treatments CL_IDENTIFIABILITY and CL_BASE
} 
"On a scale from 0 (very immoral) to 6 (very moral):

How moral do you see people who have traded in this experiment? (DA)

How moral do you see people who have NOT donated in this experiment? (CL)"

"On a scale from 0 (very immoral) to 6 (very moral):

How moral do you see people who have NOT traded in this experiment? (DA)

How moral do you see people who have donated in this experiment? (CL)"

In regime CL the average scores are 2.53 for the first question and 4.41 for the second question. The reported difference between both questions is highly significant (Wilcoxon signed-ranks test, $p=0.000, N=115$ ). ${ }^{17}$ We obtain similar results for regime DA, where average scores are 3.05 for the first question and 4.62 for the second question (Wilcoxon signed-ranks test, $p=0.000, N=255$ ) The results from the questionnaire show that participants have a concise view on what is the moral action to take and what is not.

\section{Conclusion}

By testing two different institutional regimes we have investigated whether several different interventions could prevent or reduce moral erosion in laboratory experiments. We have shown that specific interventions can affect the extent of moral behavior, yet not all of them do, and not in all regimes studied here.

The common ground that we found across both regimes is that the threat of monetary punishment increases the level of donations and subjects get more moral by taking less often money for themselves instead of donating it to UNICEF. Moreover, both regimes also share the feature that getting subjects more involved with the traded good - here by letting a physician explain the risks and the actual death toll of measles and how vaccination can help to prevent that - does not change behavior. Relating this finding to the real world outside the laboratory suggests that information campaigns and "name and shame"-campaigns might have limited effects, if any.

Both regimes differ with respect to the influence of removing a subject's

\footnotetext{
${ }^{17}$ Including the answers for CL_PUNISHMENT_MILD, scores are 2.54 and 4.33 , respectively. The Wilcoxon signed-ranks test shows similar results: $p=0.000, N=185$.
} 
anonymity. While this intervention had no influence on behavior in the DAmarket, it did have one in the CL-regime. We believe that removed anonymity in our choice list regime works better than in the double-auction regime as there is no diffusion of responsibility in the former and because in the DA-regime subjects observe a large degree of trading, thus making it somewhat socially more acceptable.

Overall, our paper had the goal to study whether and how different interventions might have an influence on the degree of morality when subjects can make decisions that can generate negative externalities on uninvolved parties. By considering two fairly different regimes we have exposed the various interventions to a kind of robustness check, finding common ground, respectively effects, for two interventions, but different effects for a third one. We consider these important steps for a better understanding of how institutional rules governing markets or individual decision making - affect moral behavior. Both society on a more general level and companies in particular can benefit from such knowledge that may help to design rules that promote compliance with ethical norms and standards. 


\section{References}

Ariely, Dan, Anat Bracha, Stephan Meier. 2009. Doing good or doing well? image motivation and monetary incentives in behaving prosocially. American Economic Review 99 544-555.

Bartling, Björn, Roberto Weber. 2014. Do markets erode social responsibility? Working Paper .

Bock, Olaf, Andreas Nicklisch, Ingmar Baetge. 2012. hroot: Hamburg recruitment and organization online tool. Working Paper .

Bolton, Gary, Axel Ockenfels. 2012. Behavioral economic engineering. Journal of Economic Psychology 33 665-676.

Ciccarelli, Saundra K., Noland J. White. 2009. Psychology. Pearson Education, New Jersey.

Darley, John, Bibb Latane. 1968. Bystander intervention in emergencies: diffusion of responsibility. Journal of Personality and Social Psychology 8 377-383.

Falk, Armin, Nora Szech. 2013. Morals and markets. Science 340 707-711.

Fehr, Ernst, Urs Fischbacher. 2004. Third party punishment and social norms. Evolution and Human Behavior 25 63-87.

Fischbacher, Urs. 2007. z-tree: Zurich toolbox for ready-made economic experiments. Experimental Economics 10(2) 171-178.

Friedman, Milton. 1962. Capitalism and Freedom. The University of Chicago Press.

Gintis, Herbert, Samuel Bowles, Robert Boyd, Ernst Fehr. 2003. Explaining altruistic behavior in humans. Evolution and Human Behavior 24 153-172.

Greiner, Ben. 2004. Forschung und wissenschaftliches Rechnen 2003, An Online Recruitment System for Economic Experiments. GWDG Bericht 63. Gesellschaft fuer Wissenschaftliche Datenverarbeitung, Goettingen, 79-93. 
Krupka, Erin, Roberto Weber. 2009. The focusing and informational effects of norms on pro-social behavior. Journal of Economic Psychology 30 307-320.

Leibbrandt, Andreas, Raúl López-Pérez. 2012. An exploration of third and second party punishment in ten simple games. Journal of Economic Behavior E Organisation 84 753-766.

Marx, Karl. 1904. A Contribution to the Critique of Political Economy. Kerr (Chicago).

Masclet, David, Charles N. Noussair, Steven Tucker, Marie-Claire Villeval. 2003. Monetary and nonmonetary punishment in the voluntary contributions mechanism. American Economic Review 93(1) 366-380.

McCloskey, Deirdre. 2006. The Bourgeois Virtues. University of Chicago Press.

Roth, Alvin E. 2002. The economist as engineer: Game theory, experimentation, and computation as tools fo design economics. Econometrica 70(4) 13411378.

Sandel, Michael. 2012. What Money Can't Buy: The Moral Limits of Markets. Farrar, Straus and Grioux (New York).

Shleifer, Andrei. 2004. Does competition destroy ethical behavior? The American Economic Review 94 414-418.

Simmel, Georg. 1990. The Philosophy of Money. Routledge (London and New York).

Weber, Max. 1978. Economy and Society. University of California Press (Berkeley).

White, Halbert. 1980. A heteroskedasticity-consistent covariance matrix and a direct test for heteroskedasticity. Econometrica $\mathbf{4 8}$ 817-838. 


\section{Appendix}

\subsection{Additional Figures and Tables}

\subsubsection{Regime CL}

Table A1 indicates pairwise coefficient tests of the independent variable of Table

1. We find no significant difference between treatments.

Table A1: Coefficient tests of the regression in Table 1.

\begin{tabular}{lcc}
\hline \hline & Coefficient tests for variable SWITCHING POINT \\
& CL_IDENTIFIABILITY & CL_PUNISHMENT \\
\hline CL_PHYSICIAN & 1.64 & 2.29 \\
CL_IDENTIFIABILITY & & 0.12 \\
\hline \hline
\end{tabular}

Coefficient tests for variable SWITCHING POINT. The numbers indicate $C h i^{2}$-values.

$*, * *$ and $* * *$ represent the $10 \%, 5 \%$ and the $1 \%$ significance levels of a two-sided test. 


\subsubsection{Regime DA}

Table A2 indicates pairwise coefficient tests of the independent variables of

Table 2. The top panel shows tests for Model (1) for the variable TRADES.

We observe that DA_PUNISHMENT shows significantly fewer trades and hence more moral behavior compared to all other treatments of regime DA.

Table A2: Coefficient tests of the regression in Table 2.

\begin{tabular}{lccc}
\hline \hline & \multicolumn{3}{c}{ Coefficient tests for variable TRADE } \\
& DA_PHYSICIAN & DA_IDENTIFIABILITY & DA_PUNISHMENT \\
\hline DA_RESPONSIBILITY & 0.01 & 0.06 & $3.42^{*}$ \\
DA_PHYSICIAN & & 0.16 & $3.39^{*}$ \\
DA_IDENTIFIABILITY & & & $8.92^{* * *}$ \\
\hline \hline
\end{tabular}

Top: coefficient tests for variable TRADE. The numbers indicate $C h i^{2}$-values.

$*,{ }^{*}$ and ${ }^{* * *}$ represent the $10 \%, 5 \%$ and the $1 \%$ significance levels of a two-sided test. 


\subsubsection{Robustness Check Treatment CL_PUNISHMENT_MILD}

We also run a "milder" version of the punishment treatment in the CL-regime, treatment CL_PUNISHMENT_MILD. This is identical to CL_PUNISHMENT, with the only difference in the displayed information about the assigned subjects. In CL_PUNISHMENT_MILD observers only see whether their assigned subjects took money for themselves by having chosen the payout in the randomly selected choice pair or donated by having chosen the donation in the randomly selected choice pair in the last period and for all periods. In CL_PUNISHMENT_MILD the observers are less involved as they receive fewer information on the behavior of the subjects and the random component of picking one out of the 22 decision pairs for implementation may make punishers less willing to punish. ${ }^{18}$ For this reason, we expect that subjects consider the threat of punishment in DA_PUNISHMENT as well as CL_PUNISHMENT more severely than in CL_PUNISHMENT_MILD.

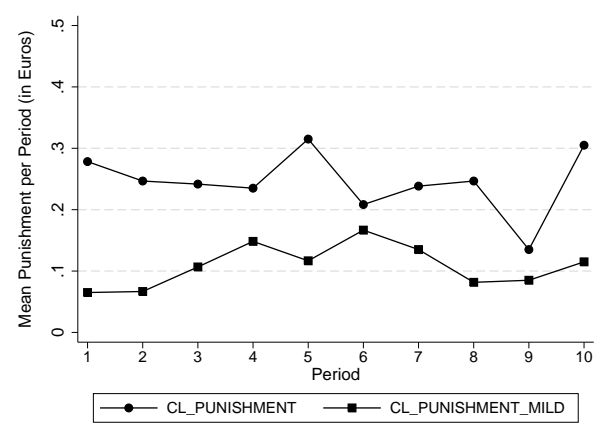

Figure A1: Average amount of Euro spent for punishment per subject and period in treatment CL_PUNISHMENT and CL_PUNISHMENT_MILD.

Figure A1 shows the average amount of Euros spent for punishment per market participant and period in CL_PUNISHMENT and CL_PUNISHMENT_MILD. It is evident that punishment is significantly higher in treatment CL_PUNISHMENT

\footnotetext{
${ }^{18}$ For instance, one subject in CL_PUNISHMENT_MILD could donate to UNICEF in 20 out of 22 choice pairs. If one of the two other cases is drawn for payment, the only information the punisher can observe is that the subject has taken the money for himself, but must remain uncertain about the subject's choices in the non-chosen choice pairs. This may inhibit a tendency to punish someone who is observed (for a randomly chosen choice pair) not to have donated.
} 
compared to CL_PUNISHMENT_MILD (mean punishment in CL_PUNISHMENT_MILD is 0.11 Euro and in CL_PUNISHMENT 0.25 Euro; Wilcoxon signed-ranks test, $p=0.015, N=120)$. This indicates that with more information, punishment is significantly higher.

Furthermore we find that subjects do not switch from the donation to the individual payment at significantly higher individual payments in treatment CL_PUNISHMENT_MILD compared to the baseline CL_BASE (see Figure A2). Conducting the same regression as reported in Table 1 including also CL_PUNISHMENT_MILD shows that the coefficients are insignificant for CL_PUNISHMENT_MILD ( $p=0.699$ in Model (1) and $p=0.261$ in Model (2)). Since, in contrast to CL_PUNISHMENT, CL_PUNISHMENT_MILD shows no significant effect, we conclude that information matters for punishment choices of observers as well as the effectiveness of punishment. 

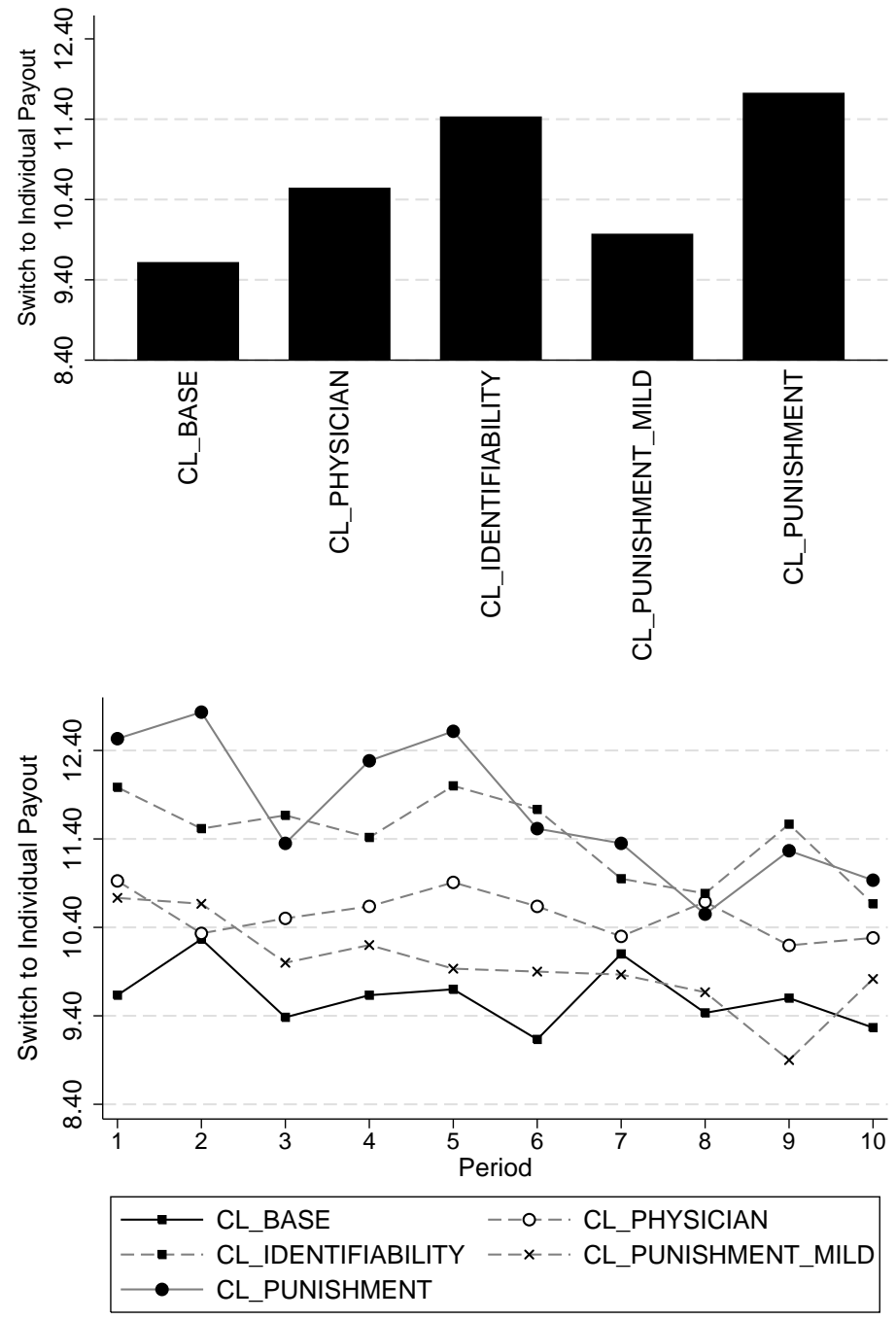

Figure A2: TOP: Average amount of money where subjects switch from donating money to UNICEF to taking the money for themselves. BOTTOM: Average amount of money where subjects switch over time. 


\subsubsection{Robustness Check: Additional Regressions for CL}

Table A3: Additional regressions for subjects' switching from the donation to the individual payment in the CL-treatments.

\begin{tabular}{lcc}
\hline \hline & Ordered probit regression & Negative Binomial Regression \\
& SWITCHING POINT & SWITCHING POINT \\
\hline CL_PHYSICIAN & 0.107 & 0.096 \\
& $(0.821)$ & $(1.148)$ \\
CL_IDENTIFIABILITY & $0.288^{* *}$ & $0.180^{* *}$ \\
& $(2.081)$ & $(2.073)$ \\
CL_PUNISHMENT & $0.319^{* *}$ & $0.206^{* *}$ \\
& $(2.025)$ & $(2.248)$ \\
$\alpha$ & $\cdot$ & $2.221^{* * *}$ \\
& & $(31.042)$ \\
\hline$N$ & & 2390 \\
$p$-value of $F$-test & 2390 & 0.081 \\
\hline \hline
\end{tabular}

Dependent variable: number of the choice pair where subject $i$ switches from donating to UNICEF to preferring the individual payment (SWITCHING POINT). The variable ranges from 0 (the subject always takes the individual payment) to 22 (the subject always donates). Binary dummy variables for each treatment serve as independent variables. Treatment CL_BASE is the benchmark and is therefore captured with the intercept $\alpha$. Standard errors on a cohort level (i.e., the cohort of subjects that constitute an experimental session) are clustered to account for correlations between subjects. $z$-values are given in parentheses.

$*$, ** and ${ }^{* * *}$ represent the $10 \%, 5 \%$ and the $1 \%$ significance levels of a two-sided test. 


\subsubsection{Regressions on Observer Behavior}

Table A4: GLS panel regression for the amount of punishment in CL_PUNISHMENT.

\begin{tabular}{lc}
\hline \hline & PUNISHMENT \\
\hline SWITCHING POINT & $-0.011^{* *}$ \\
PAYOUT & $(-2.499)$ \\
& $0.079^{* *}$ \\
PERIOD & $(2.570)$ \\
& $-0.007^{* * *}$ \\
$\alpha$ & $(-5.189)$ \\
& $0.240^{* * *}$ \\
$N$ & $(3.861)$ \\
$p$-value of $F$-test & 600 \\
\hline \hline
\end{tabular}

Dependent variable: amount used for punishment for a subject $i$ by an observer $o$ relative to the total amount spent by the observer $o$ (PUNISHMENT). Explanatory variables: number of the choice pair where a subject switches from donating to UNICEF to preferring the individual payment (SWITCHING POINT). The variable ranges from 0 (the subject always takes the individual payment) to 22 (the subject always donates). Binary dummy variable indicating whether a subject received an individual payout in the last period (PAYOUT). Variable for the period (PERIOD). Standard errors on a cohort level (i.e., the cohort of subjects that constitute a experiment session) are clustered to account for correlations between subjects. $z$-values are given in parentheses.

$*, * *$ and ${ }^{* * *}$ represent the $10 \%, 5 \%$ and the $1 \%$ significance levels of a two-sided test. 
Table A5: GLS panel regression for the amount of punishment in DA_PUNISHMENT.

\begin{tabular}{lc}
\hline \hline & PUNISHMENT \\
\hline TRADING & $0.139^{* * *}$ \\
& $(3.166)$ \\
PERIOD & -0.003 \\
& $(-0.959)$ \\
$\alpha$ & 0.034 \\
& $(1.321)$ \\
\hline$N$ & 800 \\
$p$-value of $F$-test & 0.006 \\
\hline \hline
\end{tabular}

Dependent variable: amount used for punishment for a subject $i$ by an observer $o$ relative to the total amount spent by the observer $o$ (PUNISHMENT). Explanatory variables: Binary dummy variable indicating whether a subject traded in the last period (TRADING). Variable for the period (PERIOD). Standard errors on a market level are clustered to account for correlations between subjects. $z$-values are given in parentheses.

$*, * *$ and ${ }^{* * *}$ represent the $10 \%, 5 \%$ and the $1 \%$ significance levels of a double-sided test. 


\subsection{Transaction Data of Individual Markets in Regime DA}
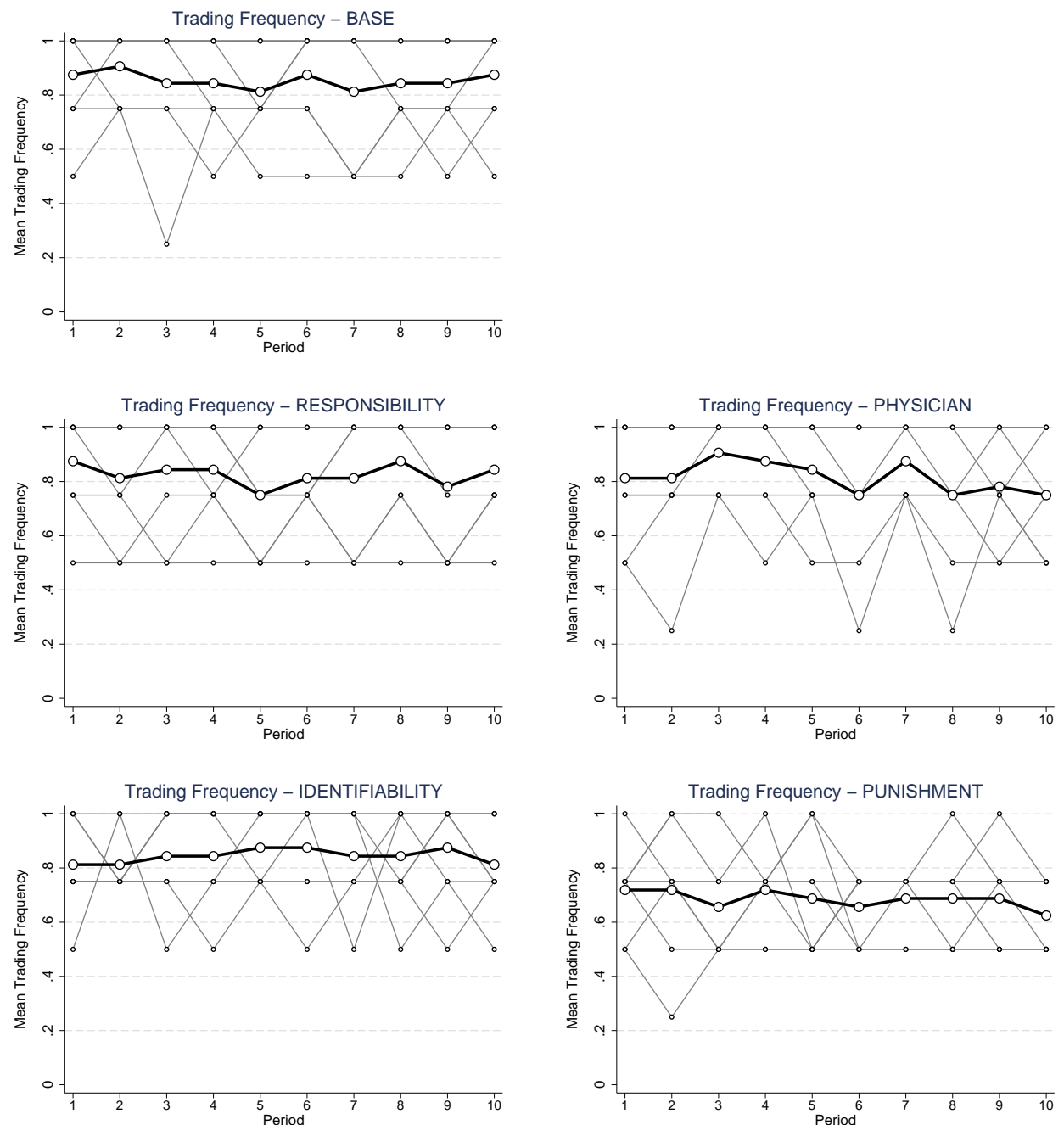

Figure A3: Relative trading frequency (number of trades divided by the number of possible trades per period) over time in the various double-auction market treatments. Thin grey lines: relative trading frequency of individual markets. Bold line: treatment average. 


\subsection{Price Data of Individual Markets in Regime DA}
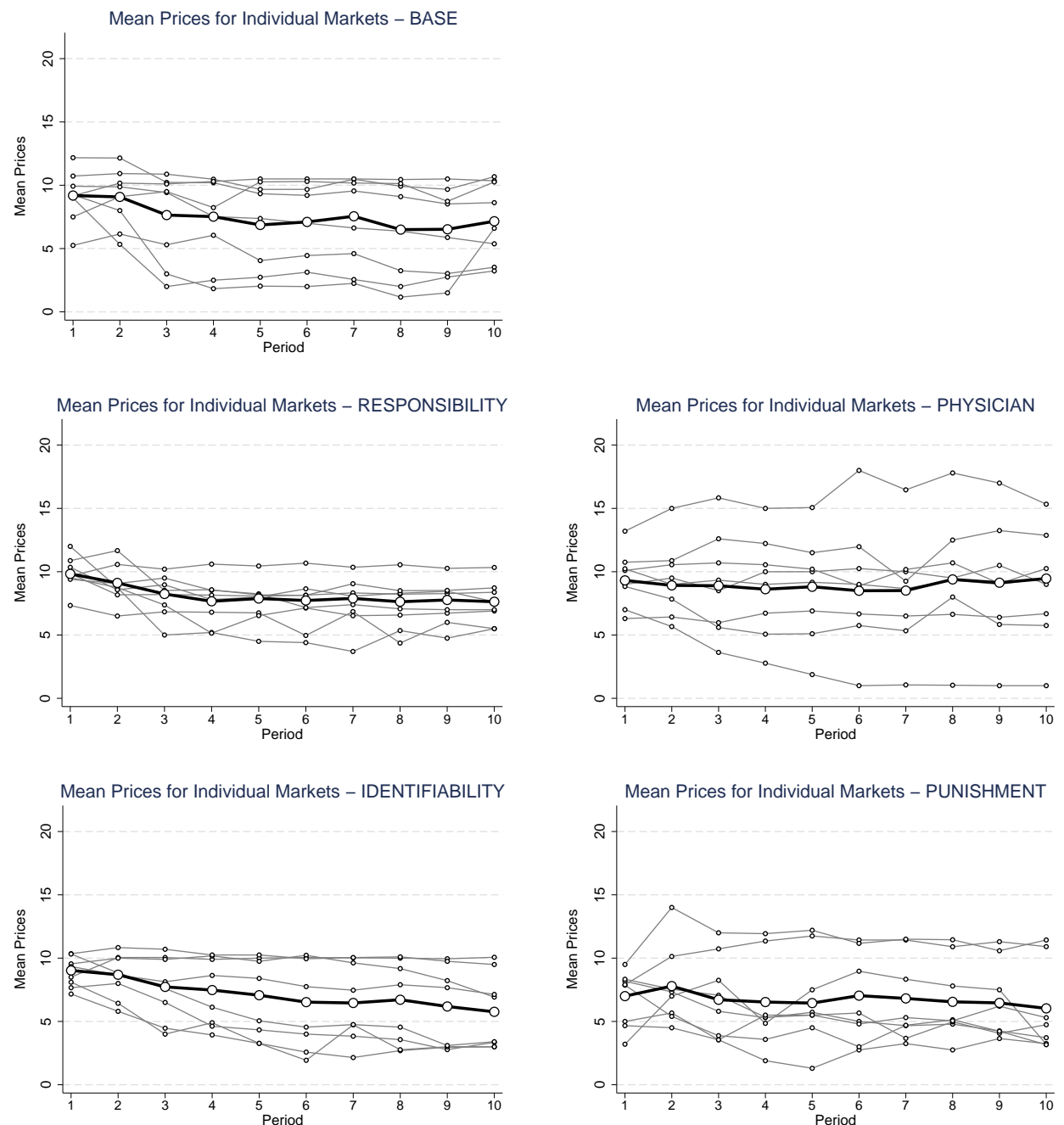

Figure A4: Average market prices over time in the various double-auction market treatments. Thin grey lines: mean period prices of individual markets. Bold line: volume-weighted mean treatment prices. 


\subsection{Instructions for the Experiments}

In the following we provide an English translation of the instructions for the market treatment DA_BASE and the individual treatment CL_BASE (see Section 5.4.1 and Section 5.4.3). Minimal changes to the instructions for treatments DA_RESPONSIBILITY and DA_IDENTIFIABILITY are highlighted in Section 5.4.1, those for CL_IDENTIFIABILITY in Section 5.4.3. The instructions for treatment DA_PUNISHMENT are presented in section 5.4.2, those for treatment CL_PUNISHMENT in 5.4.4. Instructions for treatment DA_PHYSICIAN and CL_PHYSICIAN were identical to those of DA_BASE and CL_BASE, respectively, but an additional text (see Section 5.6) was read out to subjects (and shown on PowerPoint slides, see Section 5.5). This was done after reading the instructions, accomplishing the trial period and directly before the main experiment started. ${ }^{19}$ German or English Versions for all treatments are available on request.

\subsubsection{Instructions for Treatments DA_BASE, DA_RESPONSIBILITY, DA_IDENTIFIABILITY and DA_PHYSICIAN.}

Thank you very much for participating in the experiment!

For your participation you will in any case receive 10 Euro. You can earn an additional amount of money. At the end of the experiment you will receive your money from a researcher who is not present in the room during the experiment. Neither the other participants of the experiment nor the experimenter will be able to see how much money you have earned.

Please note: Throughout the whole experiment communication between the participants is not allowed. Also no use of cell phones or calculators is allowed. On the computer please only use the functions intended to be used. If you do not abide to these rules you risk forfeiting all your earnings. If you have

\footnotetext{
${ }^{19}$ When sending out the invitations for the experiment, we included the following phrase in all treatments: "Please note that in this experiment strict anonymity could be removed, but participants will not be identified by name." However, only in treatments DA_IDENTIFIABILITY and CL_IDENTIFIABILITY we made use of this provision.
} 
questions please raise your hand. Your question will then be answered at your cubicle!

All statements made in these instructions are true. Your decisions in this experiment will not be known to any other participant, i.e., your anonymity is ensured.

[Alternative text in treatment DA_IDENTIFIABILITY: Instead of the above sentence the following sentences were written: All statements made in these instructions are true. For the payment you are separately called by seat number. After payment you have to go back to your seat to fill out a final questionnaire.]

\section{Overview over the experiment}

In this experiment you trade in a market with a total of 10 traders in a sequence of 10 periods. 6 sellers can sell to 4 buyers for a maximum price of 21.40 Euro. There are hence more sellers than buyers.

You will learn at the beginning of the experiment whether you are buyer or seller. Your role will remain unchanged over all 10 periods. Each trading period lasts 3 minutes.

If there is no trade the amount of 21.40 Euro is not divided between buyer and seller, but instead for each person who has not traded a donation of 10.70 Euro will be made to UNICEF by the experimenters. A donation of 10.70 Euro represents half of a package of 100 doses of measles vaccine (see below for more details). Hence, for every two people who do not trade this adds up to 21.40 Euro, which represents a full package of measles vaccine.

If a trade happens between a buyer and a seller, the 21.40 Euro are distributed between them, depending on the transaction price (details follow below). In this case no donation is made. Thus in the sequence of 10 periods you can decide whether you claim money for yourself and a trading partner, or have money donated to UNICEF.

\section{Detailed information on the market}


- In each trading period the computer opens a new market. In each period the same 10 people participate in the market.

- A buyer can submit offers to buy to all sellers. Each seller can submit offers to sell to all buyers. Own offers are written in blue on the trading screen.

You can enter your offers on the trading screen (shown below). All prices between 0 and 21.40 Euro in steps of 10 Eurocents are allowed. Possible prices are thus $0 €, 0.10 €, 0.20 €, 0.30 €$, etc. up to $21.40 €$.

- A trade is concluded if a buyer accepts an offer to sell from a seller or a seller accepts an offer to buy of a buyer. No separate confirmation by the buyer or seller who made the offer is necessary.

A buyer can accept an offer to sell and a seller an offer to buy at any time. Only the best offers can be accepted. The best offers are written on top of the lists of all offers to buy/sell and are highlighted. If you want to accept an offer, click the "SELL"-, respectively "BUY"-button at the bottom of the trading screen. Doing so you conclude a trade with the buyer/seller who submitted the best offer to buy/sell.

Each trading period you can make a maximum of one trade. This means once you concluded one trade this period, you cannot accept offers or submit own offers in this period. Once a trader has concluded a trade all his open offers are deleted from the list of open offers.

On the top right of the trading screen you always see the remaining trading time.

If you do not conclude a trade in a given period, then 10.70 Euro are donated to UNICEF for each person who did not trade if that period is chosen for payment (see below for details on payment).

- No trader knows with whom in the room he/she has traded, i.e., your anonymity is ensured.

[Alternative text in treatment DA_IDENTIFIABILITY: At the end of each trading period you will see on a screen which traders (identified by seat 
number but not name) have traded in this period and which have not traded. You also see how often each subject has traded in all previous periods.

Please note: Because of this screen and the payment mechanism described above there is no strict anonymity in this experiment.]

Example of the Trading Screen for a seller can be seen below.

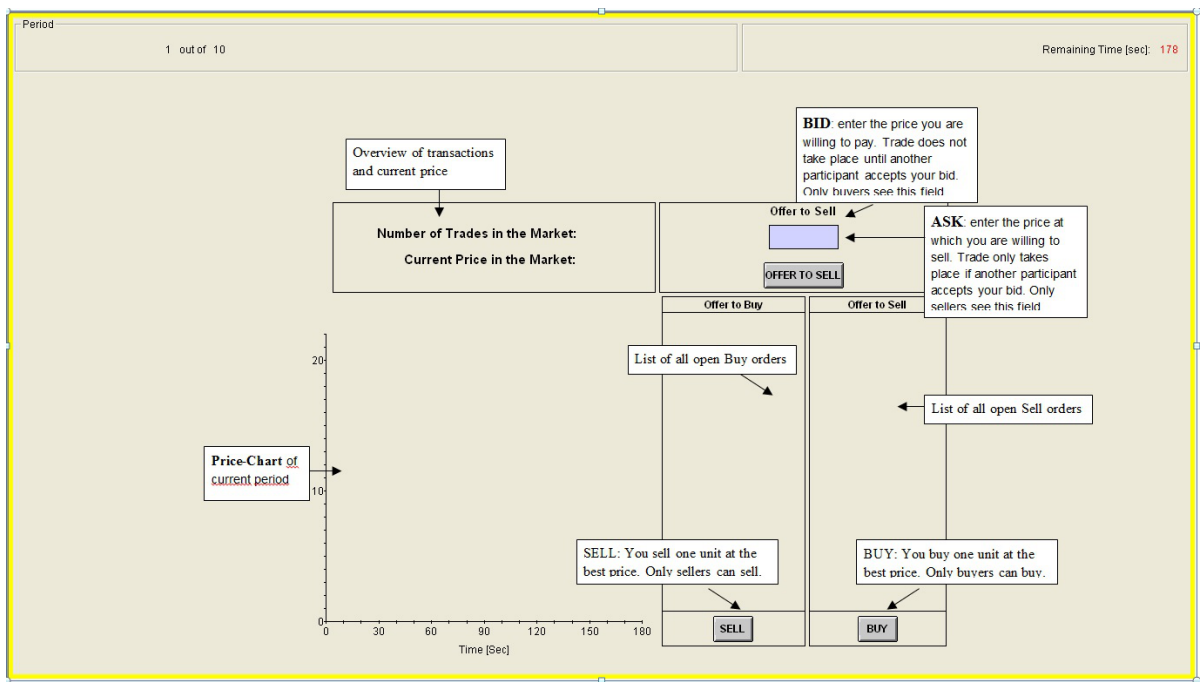

\section{Payment}

One of the 10 periods is randomly selected. This period is then relevant for payment. The payment from this randomly chosen period is added to the initial endowment of 10 Euro.

How is the payment calculated for a buyer for a randomly selected period?

- When the buyer trades then she earns

$$
\text { Earnings of a buyer }=21.40 \text { - accepted price }
$$

- If a buyer does not trade she earns zero in this part of the experiment. Instead, 10.70 Euro are donated to UNICEF on behalf of this trader (as each trader needs a counterpart for a transaction, the two non-trading subjects are responsible for a total donation of 21.40 Euro.) 
How is the payment calculated for a seller for a randomly selected period?

- If a seller trades she earns

$$
\text { Earnings of a seller }=\text { accepted price }
$$

- If a seller does not trade she earns zero in this part of the experiment. Instead, 10.70 Euro are donated to UNICEF on behalf of this trader (as each trader needs a counterpart for a transaction, the two non-trading subjects are responsible for a total donation of 21.40 Euro.)

\section{Details on the donation}

A donation of 10.70 Euro represents half of a package of 100 doses of measles vaccine (see below for more details). Hence, two decisions for Alternative B add up to a full package of measles vaccine. From the randomly selected period the selections of Alternative B by all subjects are added up and the money is donated to UNICEF by the experimenters. This is done for all sessions of the experiment. If one half-package of vaccine would be missing, the experimenters would contribute this. A receipt/confirmation of the donation to UNICEF will be sent to you within a month of this experimental session to allow you to verify the correctness of the statements made here.

\section{Summary outline}

In the market 4 buyers and 6 sellers can trade. Buyers and sellers can make price offers, but they need not.

If a price offer is accepted a trade is concluded. The seller earns the price, the buyer earns 21.40 minus the price. In total there are 10 trading periods. Each buyer and each seller can conclude a maximum of one trade per period. [Additional text in treatment DA_IDENTIFIABILITY: After each period there is a screen showing, by seat number, who has and who has not traded in that period and how often each subject has traded in all previous periods.]

At the end of the experiment one period is randomly selected to be implemented with all consequences for payments and donations. If a trade was 
concluded in that period, there will be no donation to UNICEF on behalf of the two involved traders, but the 21.40 Euro are divided among the buyer and seller (depending on the price). For each subject that does not trade 10.70 Euro (and hence 21.40 Euro for two traders) are donated to UNICEF to buy a package of measles vaccine.

Before the 10 periods start there will be one training period, which is not relevant for your payment. This training period serves to familiarize you with the decision screen and sequence.

Please note: By participating in the experiment you confirm that you have understood the rules and that you participate voluntarily. After finishing reading the instructions you have two minutes to decide whether you see a moral conflict which you want to avoid. In this case you can now leave the experiment. You will then get 10 Euro for the time you have spent.

Appendix 1: Excerpt from the donation information of UNICEF (Source: UNICEF, translation from the German version at https://www.unicef.at/stores/connect/shoparticle/masern-impfstoff-30-stuck/ shop/catalog/product/view/208/shop_for_life/)

Measles vaccine, 100 doses Article-Nr. S359163

Measles are highly infectious and very often deadly. Each day hundreds of children become victims of this disease. The survivors often suffer consequences for their whole life, like blindness or brain damages. This, even though protecting the children would be so easy to prevent.

Measles are extremely infectious and spread especially fast when many people live densely together, as in refugee camps. Especially with weakened children 
the disease often ends deadly or leads to lasting physical or mental damages. Measles are one of the main caused for blindness among children and often become critical when no medical help is available. This, even though measles vaccination offers quick, reliable, and cheap protection. UNICEF conducts major vaccination campaigns, especially after natural disasters and in other emergency situations, to prevent the spreading of the disease. With a measles vaccination you do not only protect the children, but you also reduce the risk for all who get in contact with them.
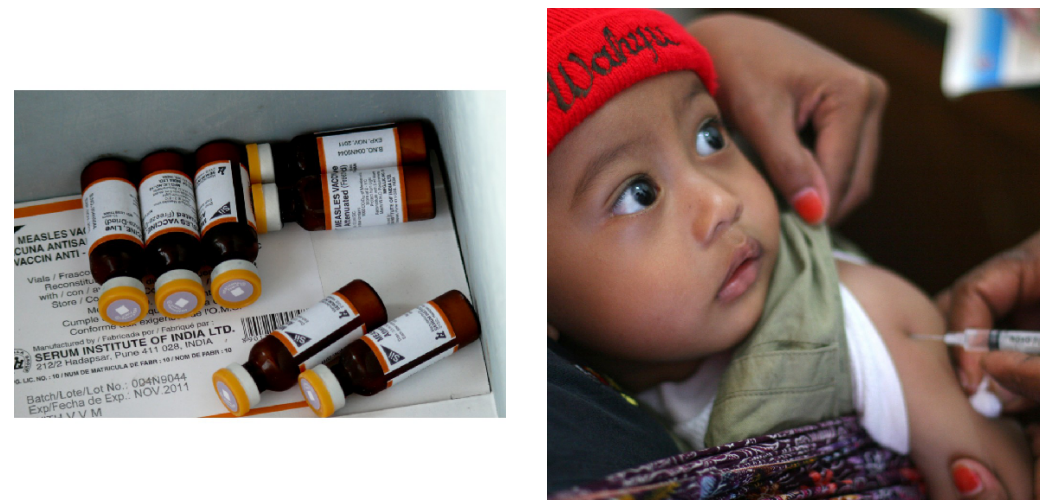

Figure A5: Left: (c) UNICEF/ NYHQ06-1800/ Josh Estey; Right: (c) UNICEF/ NYHQ2010-1454/ Christine Nesbitt. 


\subsubsection{Instructions for Treatment DA_PUNISHMENT}

Thank you very much for participating in the experiment!

For your participation you will in any case receive 10 Euro. You can earn an additional amount of money. At the end of the experiment you will receive your money from a researcher who is not present in the room during the experiment. Neither the other participants of the experiment nor the experimenter will be able to see how much money you have earned.

Please note: Throughout the whole experiment communication between the participants is not allowed. Also no use of cell phones or calculators is allowed. On the computer please only use the functions intended to be used. If you do not abide to these rules you risk forfeiting all your earnings. If you have questions please raise your hand. Your question will then be answered at your cubicle!

All statements made in these instructions are true. Your decisions in this experiment will not be known to any other participant, i.e., your anonymity is ensured.

\section{Overview over the experiment}

In this experiment 12 subjects form one cohort, 10 of which are "Players A" and two are "Players B". The roles do not change over the 10 periods of the experiment.

\section{Decisions of Players A}

As a Player A you trade in a market with a total of 10 traders in a sequence of 10 periods. 6 sellers can sell to 4 buyers for a maximum price of 21.40 Euro. There are hence more sellers than buyers. You will learn at the beginning of the experiment whether you are buyer or seller. Your role will remain unchanged over all 10 periods. Each trading period lasts 3 minutes.

If there is no trade the amount of 21.40 Euro is not divided between buyer 
and seller, but instead for each person who has not traded a donation of 10.70 Euro will be made to UNICEF by the experimenters. A donation of 10.70 Euro represents half of a package of 100 doses of measles vaccine (see below for more details). Hence, for every two people who do not trade this adds up to 21.40 Euro, which represents a full package of measles vaccine.

If a trade happens between a buyer and a seller, the 21.40 Euro are distributed between them, depending on the transaction price (details follow below). In this case no donation is made. Thus in the sequence of 10 periods you can decide whether you claim money for yourself and a trading partner, or have money donated to UNICEF.

\section{Detailed information on the market}

- In each trading period the computer opens a new market. In each period the same 10 people participate in the market.

- A buyer can submit offers to buy to all sellers. Each seller can submit offers to sell to all buyers. Own offers are written in blue on the trading screen.

You can enter your offers on the trading screen (shown below). All prices between 0 and 21.40 Euro in steps of 10 Eurocents are allowed. Possible prices are thus $0 €, 0.10 €, 0.20 €, 0.30 €$, etc. up to $21.40 €$.

- A trade is concluded if a buyer accepts an offer to sell from a seller or a seller accepts an offer to buy of a buyer. No separate confirmation by the buyer or seller who made the offer is necessary.

A buyer can accept an offer to sell and a seller an offer to buy at any time. Only the best offers can be accepted. The best offers are written on top of the lists of all offers to buy/sell and are highlighted. If you want to accept an offer, click the "SELL"-, respectively "BUY"-button at the bottom of the trading screen. Doing so you conclude a trade with the buyer/seller who submitted the best offer to buy/sell.

Each trading period you can make a maximum of one trade. This means 
once you concluded one trade this period, you cannot accept offers or submit own offers in this period. Once a trader has concluded a trade all his open offers are deleted from the list of open offers.

On the top right of the trading screen you always see the remaining trading time.

If you do not conclude a trade in a given period, then 10.70 Euro are donated to UNICEF for each person who did not trade if that period is chosen for payment (see below for details on payment).

- No trader knows with whom in the room he/she has traded, i.e., your anonymity is ensured.

Example of the Trading Screen for a seller:

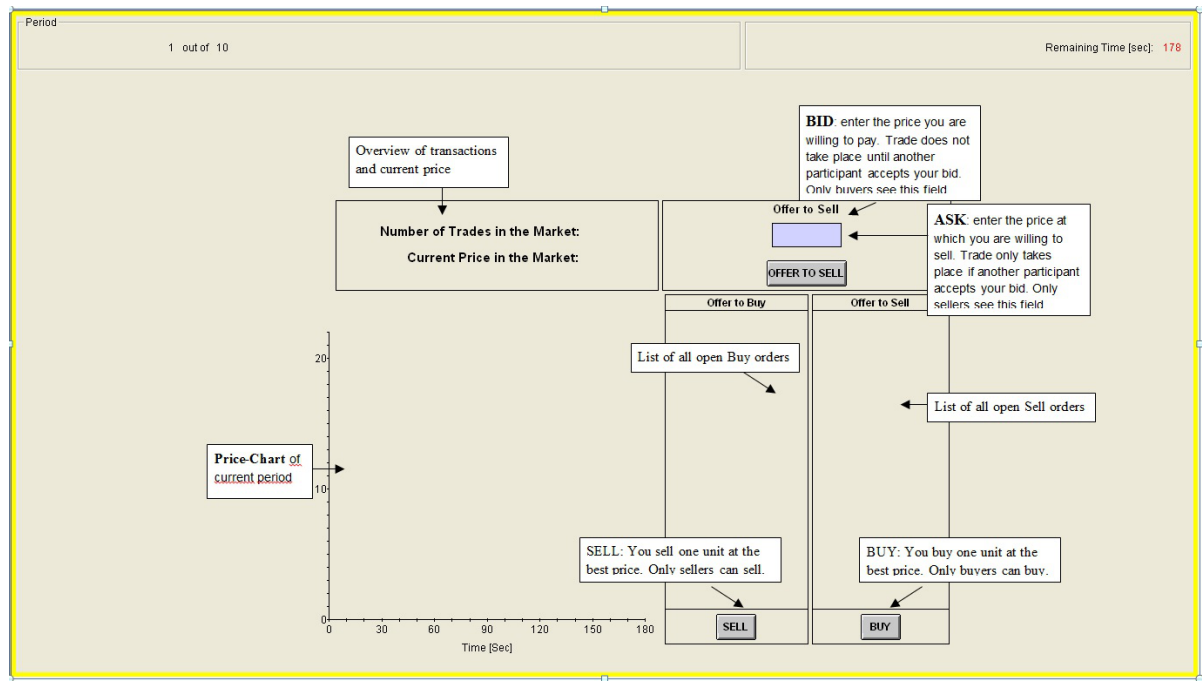

\section{Decisions of Players B}

Five Players A are assigned to each Player B. This assignment remains the same over all 10 periods. After each trading period Player B sees which Players A have traded in the respective period and which have not (identified by traderID, which is not identical to seat number). In addition Player B is informed how often each of the Players A have traded in all the preceeding periods. Player $\mathrm{B}$ receives, in addition to the 10 Euro initial endowment, an amount of 21.40 
Euro. From this total endowment Player B can assign a maximum of 3 Euro to each of the Players A assigned to him. Hence, she can assign a maximum of 15 Euro per period. Assigning Euro has the following consequences:

For Player B each assigned Euro reduces his payment by one Euro. If, e.g., Player B assigns 2 Euro to the first Player A, 1.50 Euro to the second Player A and zero Euro to each of the other three Players A, then a total of 3.50 Euro is deducted from his endowment, and hence she receives 17.90 Euro (21.40 - 2.00 $-1.50)$.

For the respective Player A each Euro assigned to him by Player B leads to a deduction of three Euro. If, e.g., 2 Euro were assigned for the first Player A, then 6 Euro (2 times 3$)$ are deducted from his earnings.

Before the next trading period starts each Player A is informed about the decision of Player B and the payment consequences for himself.

Exemplary decision screen for a Player B

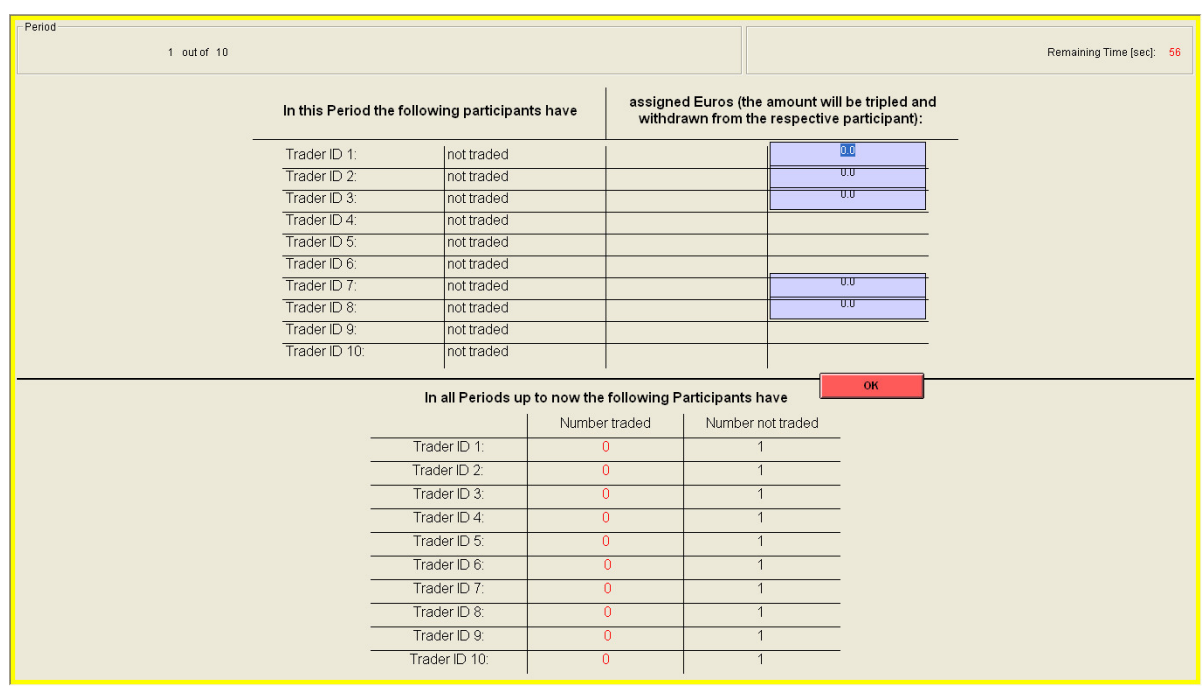

\section{Payment}

One of the 10 periods is randomly selected. This period is then relevant for payment. The payment from this randomly chosen period is added to the initial endowment of 10 Euro. 


\section{Payment Players A}

How is the payment calculated for a buyer for a randomly selected period?

- When the buyer trades then she earns

Earnings of a buyer $=21.40-$ accepted price $-3 *$ number of Euro assigned by Player B to this Player A

If the earnings of Player A are negative, the respective loss is deducted from the initial endowment of 10 Euro.

- If a buyer does not trade he earns zero in this part of the experiment. Instead, 10.70 Euro are donated to UNICEF on behalf of this trader (as each trader needs a counterpart for a transaction, the two non-trading subjects are responsible for a total donation of 21.40 Euro). If Player B assigned any Euro to the respective Player A in that period, then three times the amount assigned is deducted from the donation to UNICEF. Donation to UNICEF $=10.70-3 *$ number of Euro assigned by Player B to this Player A.

How is the payment calculated for a seller for a randomly selected period?

- If a seller trades she earns

Earnings of a seller $=$ accepted price $-3^{*}$ number of Euro assigned by Player B to this Player A

If the earnings of Player A are negative, the respective loss is deducted from the initial endowment of 10 Euro.

- If a seller does not trade she earns zero in this part of the experiment. Instead, 10.70 Euro are donated to UNICEF on behalf of this trader (as each trader needs a counterpart for a transaction, the two non-trading subjects are responsible for a total donation of 21.40 Euro). If Player B assigned any Euro to the respective Player A in that period, then three times the amount assigned is deducted from the donation to UNICEF. Donation to UNICEF $=10.70-3 *$ number of Euro assigned by Player B to this Player A. 


\section{Payment Players B}

How is the payment calculated for a Player B for a randomly selected period?

Payment to Player B $=21.40$ - sum of all points assigned to Players A in the respective period

\section{Details on the donation}

A donation of 10.70 Euro represents half of a package of 100 doses of measles vaccine (see below for more details). Hence, two decisions for Alternative B add up to a full package of measles vaccine. From the randomly selected period the selections of Alternative B by all subjects are added up and the money is donated to UNICEF by the experimenters. This is done for all sessions of the experiment. If one half-package of vaccine would be missing, the experimenters would contribute this. A receipt/confirmation of the donation to UNICEF will be sent to you within a month of this experimental session to allow you to verify the correctness of the statements made here.

\section{Summary outline}

In the market 4 buyers and 6 sellers can trade in their roles as Player A. Buyers and sellers can make price offers, but they need not.

If a price offer is accepted a trade is concluded. The seller earns the price, the buyer earns 21.40 minus the price. In total there are 10 trading periods. Each buyer and each seller can conclude a maximum of one trade per period.

At the end of each period a Player B can assign Euro to none, one or several of the Players A assigned to him. Each Euro assigned reduces Player B's earnings by one Euro. For each Player A each Euro assigned by Player B reduced his earnings by three Euro.

At the end of the experiment one period is randomly selected to be implemented with all consequences for payments and donations. If a trade was concluded in that period, there will be no donation to UNICEF on behalf of the two involved traders, but the 21.40 Euro are divided among the buyer and seller (depending on the price). For each subject who does not trade 10.70 Euro (and hence 21.40 
Euro for two traders) are donated to UNICEF to buy a package of measles vaccine. If a Player B has assigned any Euro to one or several Players A in that period, then for each Euro assigned by Player B three Euro are deducted from the respective Player A's earnings (if he traded) or the donation to UNICEF (if he has not traded). A Player B earns 21.40 minus the sum of the Euro he has assigned to Players A.

Before the 10 periods start there will be one training period, which is not relevant for your payment. This training period serves to familiarize you with the decision screen and sequence.

Please note: By participating in the experiment you confirm that you have understood the rules and that you participate voluntarily. After finishing reading the instructions you have two minutes to decide whether you see a moral conflict which you want to avoid. In this case you can now leave the experiment. You will then get 10 Euro for the time you have spent.

Appendix 1: Excerpt from the donation information of UNICEF (Source: UNICEF, translation from the German version at https://www.unicef.at/stores/connect/shoparticle/masern-impfstoff-30-stuck/ shop/catalog/product/view/208/shop_for_life/)

Measles vaccine, 100 doses Article-Nr. S359163

Measles are highly infectious and very often deadly. Each day hundreds of children become victims of this disease. The survivors often suffer consequences for their whole life, like blindness or brain damages. This, even though protecting the children would be so easy. 
ple live densely together, as in refugee camps. Especially with weakened children the disease often ends deadly or leads to lasting physical or mental damages. Measles are one of the main caused for blindness among children and often become critical when no medical help is available. This, even though measles vaccination offers quick, reliable, and cheap protection. UNICEF conducts major vaccination campaigns, especially after natural disasters and in other emergency situations, to prevent the spreading of the disease. With a measles vaccination you do not only protect the children, but you also reduce the risk for all who get in contact with them.
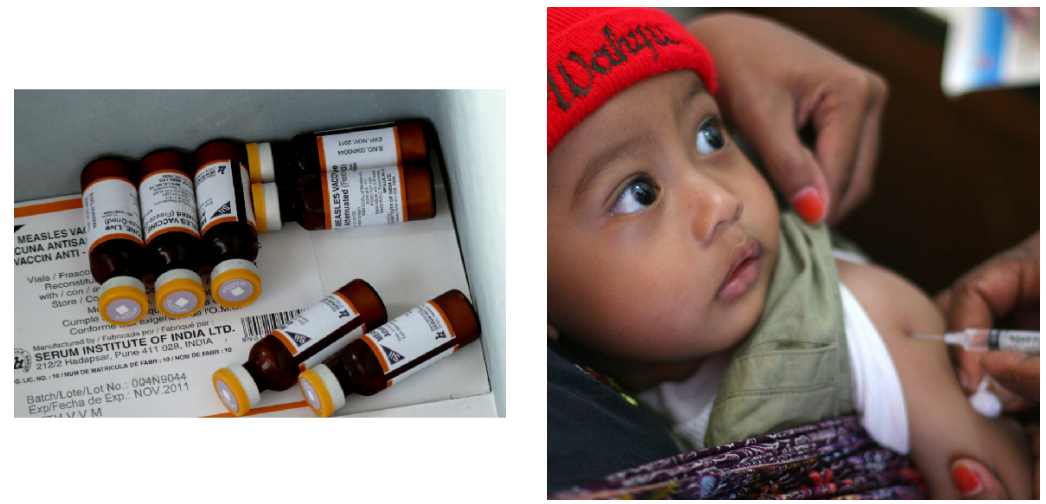

Figure A6: Left: (c) UNICEF/ NYHQ06-1800/ Josh Estey; Right: (c) UNICEF/ NYHQ2010-1454/ Christine Nesbitt. 


\subsubsection{Instructions for Treatments CL_BASE, CL_IDENTIFIABILITY and CL_PHYSICIAN}

Thank you very much for participating in the experiment!

For your participation you will in any case receive 10 Euro. You can earn an additional amount of money. At the end of the experiment you will receive your money by from a researcher who is not present in the room during the experiment. Neither the other participants of the experiment nor the experimenter will be able to see how much money you have earned.

Please note: Throughout the whole experiment communication between the participants is not allowed. Also no use of cell phones or calculators is allowed. On the computer please only use the functions intended to be used. If you do not abide to these rules you risk forfeiting all your earnings. If you have questions please raise your hand. Your question will then be answered at your cubicle!

All statements made in these instructions are true. Your decisions in this experiment will not be known to any other participant, i.e., your anonymity is ensured.

[Alternative text in treatment CL_IDENTIFIABILITY: Instead of the above sentence the following sentences were written: All statements made in these instructions are true. For the payment you are separately called by seat number. After payment you have to go back to your seat to fill out a final questionnaire.]

\section{Overview over the experiment}

In this experiment you can, in a sequence of 10 periods, decide between alternatives A and B. In each period you have 3 minutes to make your decision. Each period you will see 22 decision pairs on a screen (see screenshot below). Each decision pair consists of the following two alternatives:

- Alternative A consists of an amount of money that varies and that will be 
paid to you.

- Alternative B is a money donation of 10.70 Euro. The donation will be made to UNICEF to buy half a package of measles vaccine (details on the donation follow below).

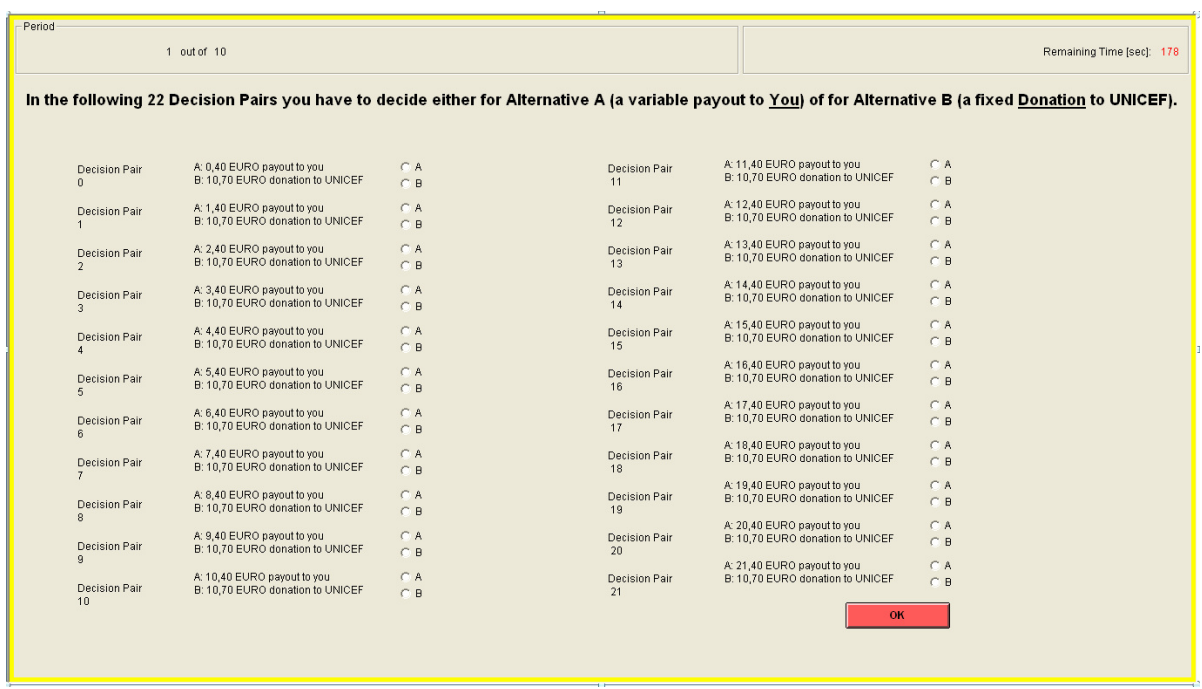

To simplify the decision (reduce your clicking effort) you can simply click on the decision pair where you start to prefer Alternative A. For all subsequent decision pairs Alternative A will be automatically marked. If you click Alternative A already in decision pair 0 (i.e., you always prefer the payment to yourself over the donation) Alternative A will be selected for all 22 decision pairs. If you select Alternative B in decision pair 21 (i.e., you always prefer to make the donation to UNICEF over a payment to yourself) Alternative B will be selected for all 22 decision pairs. You have 3 minutes for your selection.

[Additional text in treatment CL_IDENTIFIABILITY: In a first step, for your payment one of the 22 decision pairs will be selected randomly. In a second step, one of the ten periods will be selected for payment (for details see below). At the end of each period for the randomly selected decision pair of the current period you will see on a screen which traders (identified by seat number but not name) have selected a payment for themselves and which have selected a 
donation. You also see how often each subject has chosen the payment herself and how often each subject has chosen the donation in all periods conducted by then. Please note: Because of this screen and the payment mechanism described above there is no anonymity in this experiment.]

\section{Payment}

One of the 10 periods is randomly selected. This period is then relevant for payment. The payment from this randomly chosen period is added to the initial endowment of 10 Euro.

How is the payment calculated for the randomly selected period?

For your payment one of the 22 decision pairs is randomly selected from the period that was randomly selected to be the one relevant for payment. If you selected Alternative A in this randomly selected decision pair, you earn the respective amount in Euro. If you selected Alternative B, a donation of 10.70 Euro will be made to UNICEF.

\section{Details on the donation}

A donation of 10.70 Euro represents half of a package of 100 doses of measles vaccine (see below for more details). Hence, two decisions for Alternative B add up to a full package of measles vaccine. From the randomly selected period the selections of Alternative B by all subjects are added up and the money is donated to UNICEF by the experimenters. This is done for all sessions of the experiment. If one half-package of vaccine would be missing, the experimenters would contribute this. A receipt/confirmation of the donation to UNICEF will be sent to you within a month of this experimental session to allow you to verify the correctness of the statements made here.

Before the 10 periods start there will be one training period, which is not relevant for your payment. This training period serves to get you familiar with the decision screen and sequence. 
Please note: By participating in the experiment you confirm that you have understood the rules and that you participate voluntarily. After finishing reading the instructions you have two minutes to decide whether you see a moral conflict which you want to avoid. In this case you can now leave the experiment. You will then get 10 Euro for the time you have spent.

Appendix 1: Excerpt from the donation information of UNICEF

(Source: UNICEF, translation from the German version at https://www.unicef.at/stores/connect/shoparticle/masern-impfstoff-30-stuck/ shop/catalog/product/view/208/shop_for_life/)

Measles vaccine, 100 doses

Article-Nr. S359163

Measles are highly infectious and very often deadly. Each day hundreds of children become victims of this disease. The survivors often suffer consequences for their whole life, like blindness or brain damages. This, even though protecting the children would be so easy.

Measles are extremely infectious and spread especially fast when many people live densely together, as in refugee camps. Especially with weakened children the disease often ends deadly or leads to lasting physical or mental damages. Measles are one of the main causes for blindness among children and often become critical when no medical help is available. This, even though measles vaccination offers quick, reliable, and cheap protection. UNICEF conducts major vaccination campaigns, especially after natural disasters and in other emergency situations, to prevent the spreading of the disease. With a measles you do not only protect the children, but you also reduce the risk for all who get in contact with them. 

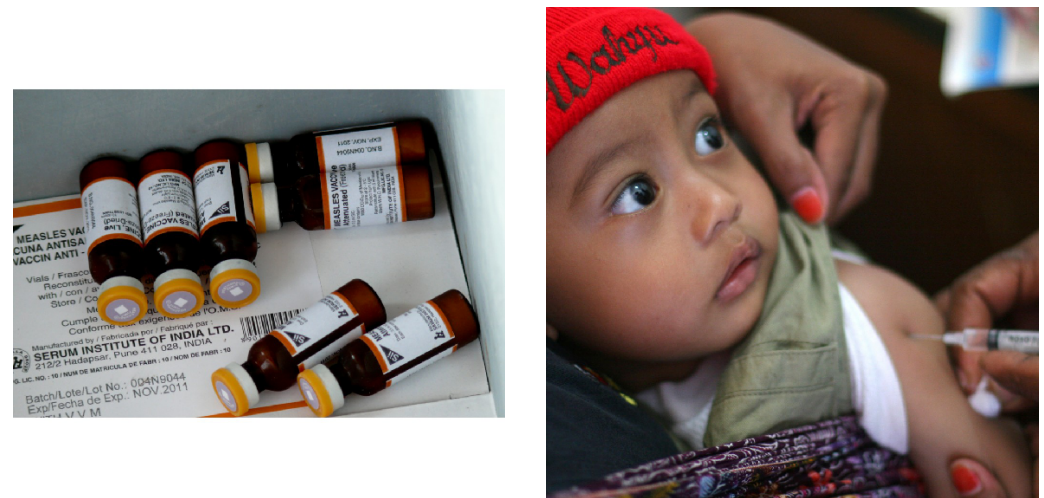

Figure A7: Left: (c) UNICEF/ NYHQ06-1800/ Josh Estey; Right: (c) UNICEF/ NYHQ2010-1454/ Christine Nesbitt. 


\subsubsection{Instructions for Treatment CL_PUNISHMENT}

Thank you very much for participating in the experiment!

For your participation you will in any case receive 10 Euro. You can earn an additional amount of money. At the end of the experiment you will receive your money by from a researcher who is not present in the room during the experiment. Neither the other participants of the experiment nor the experimenter will be able to see how much money you have earned.

Please note: Throughout the whole experiment communication between the participants is not allowed. Also no use of cell phones or calculators is allowed. On the computer please only use the functions intended to be used. If you do not abide to these rules you risk forfeiting all your earnings. If you have questions please raise your hand. Your question will then be answered at your cubicle!

All statements made in these instructions are true. Your decisions in this experiment will not be known to any other participant, i.e., your anonymity is ensured.

\section{Overview over the experiment}

In this experiment 12 subjects form one cohort, 10 of which are "Players A" and two are "Players B". The roles do not change over the 10 periods of the experiment.

\section{Decisions of Players A}

As a player A this experiment you can, in a sequence of 10 periods, decide between alternatives $\mathrm{A}$ and $\mathrm{B}$. In each period you have 3 minutes to make your decision. Each period you will see 22 decision pairs on a screen (see screenshot below). Each decision pair consists of the following two alternatives:

- Alternative A consists of an amount of money that varies and that will be 
paid to you.

- Alternative B is a money donation of 10.70 Euro. The donation will be made to UNICEF to buy half a package of measles vaccine (details on the donation follow below).

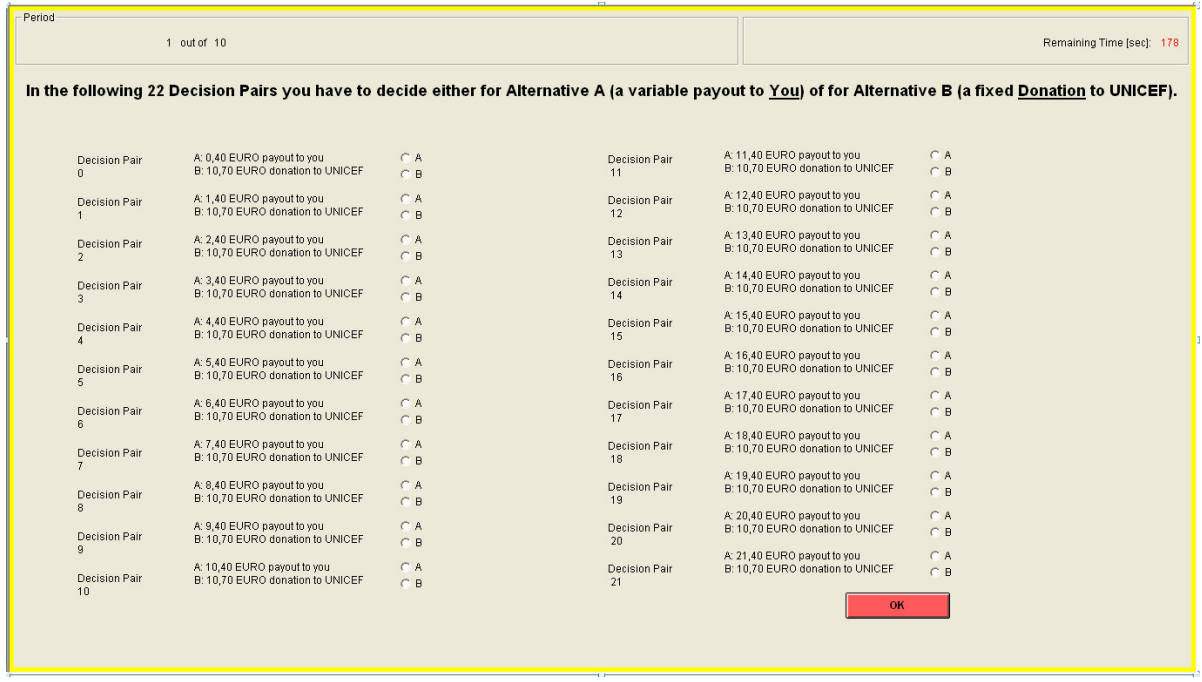

To simplify the decision (reduce your clicking effort) you can simply click on the decision pair where you start to prefer Alternative A. For all subsequent decision pairs Alternative A will be automatically marked. If you click Alternative A already in decision pair 0 (i.e., you always prefer the payment to yourself over the donation) Alternative A will be selected for all 22 decision pairs. If you select Alternative B in decision pair 21 (i.e., you always prefer to make the donation to UNICEF over a payment to yourself) Alternative B will be selected for all 22 decision pairs. You have 3 minutes for your selection.

\section{Decisions of Players B}

Five Players A are assigned to each Player B. This assignment remains the same over all 10 periods. After each period Player B sees, which Players A have chosen the payment for themselves and which have chosen the donation in the randomly drawn choice pair in the respective period (identified by trader-ID, 
which is not identical to seat number). This information is also displayed for all the preceeding periods. In addition Player B is informed about the amount of Euros from which on the own payment is is preferred to the donation as well as the amount Player A has received for the randomly drawn choice pair. Player $\mathrm{B}$ receives, in addition to the 10 Euro initial endowment, an amount of 21.40 Euro. From this total endowment Player B can assign a maximum of 3 Euro to each of the Players A assigned to him. Hence, he can assign a maximum of 15 Euro per period. Assigning Euro has the following consequences:

For Player B each assigned Euro reduces his payment by one Euro. If, e.g., Player B assigns 2 Euro to the first Player A, 1.50 Euro to the second Player A and zero Euro to each of the other three Players A, then a total of 3.50 Euro is deducted from his endowment, and hence he receives 17.90 Euro $(21.40-2.00$ $-1.50)$.

For the respective Player A each Euro assigned to him by Player B leads to a deduction of three Euro. If, e.g., 2 Euro were assigned for the first Player A, then 6 Euro (2 times 3$)$ are deducted from his earnings.

Before the next trading period starts each Player A is informed about the decision of Player B and the payment consequences for himself.

Exemplary decision screen for a Player B

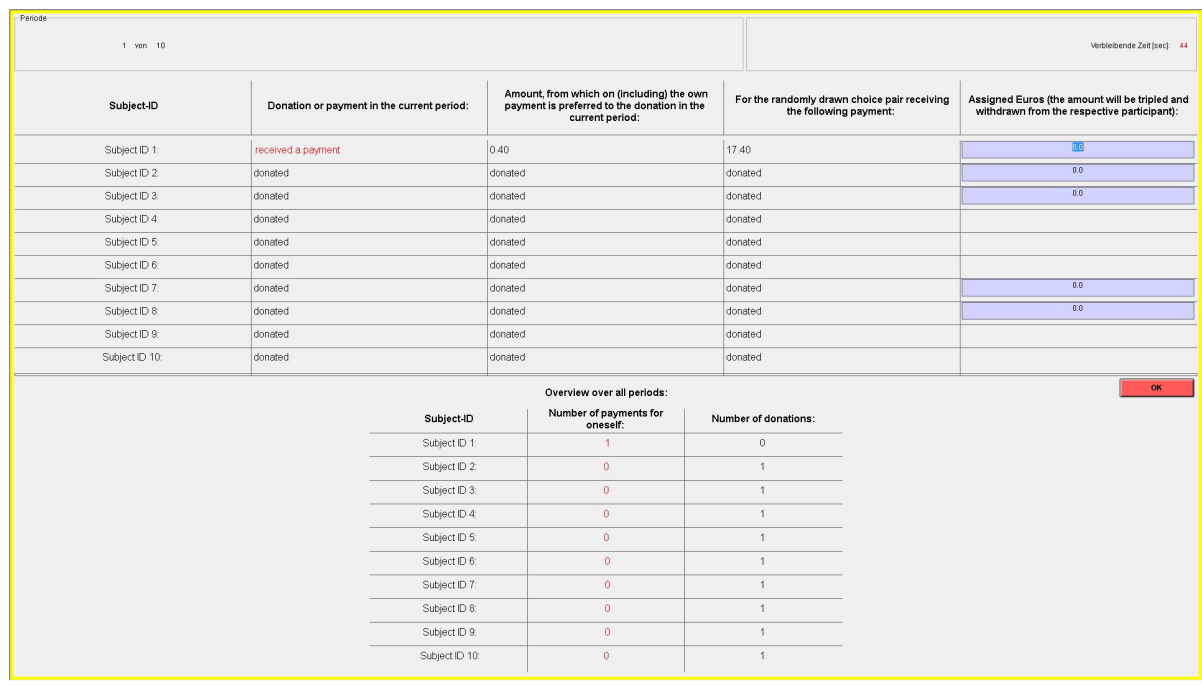




\section{Payment}

One of the 10 periods is randomly selected. This period is then relevant for payment. The payment from this randomly chosen period is added to the initial endowment of 10 Euro.

\section{Payment Player A}

For your payment one of the 22 decision pairs is randomly selected from the period that was randomly selected to be the one relevant for payment. If you selected Alternative A in this randomly selected decision pair, you earn the respective amount in Euro. If you selected Alternative B, a donation of 10.70 Euro will be made to UNICEF.

If Player B assigned any euros to the respective Player A in that period, then three times the amount assigned is deducted from the payment of Player A. If the earnings of Player A are negative, the respective loss is deducted from the initial endowment of 10 euros.

\section{Payment Player B}

Payment of Player B in Euro = 21,40 - sum of all Euros assigned to Players A in the respective period

\section{Details on the donation}

A donation of 10.70 Euro represents half of a package of 100 doses of measles vaccine (see below for more details). Hence, two decisions for Alternative B add up to a full package of measles vaccine. From the randomly selected period the selections of Alternative B by all subjects are added up and the money is donated to UNICEF by the experimenters. This is done for all sessions of the experiment. If one half-package of vaccine would be missing, the experimenters would contribute this. A receipt/confirmation of the donation to UNICEF will be sent to you within a month of this experimental session to allow you to verify the correctness of the statements made here. 
Before the 10 periods start there will be one training period, which is not relevant for your payment. This training period serves to get you familiar with the decision screen and sequence.

Please note: By participating in the experiment you confirm that you have understood the rules and that you participate voluntarily. After finishing reading the instructions you have two minutes to decide whether you see a moral conflict which you want to avoid. In this case you can now leave the experiment. You will then get 10 Euro for the time you have spent.

Appendix 1: Excerpt from the donation information of UNICEF (Source: UNICEF, translation from the German version at https://www.unicef.at/stores/connect/shoparticle/masern-impfstoff-30-stuck/ shop/catalog/product/view/208/shop_for_life/)

Measles vaccine, 100 doses

Article-Nr. S359163

Measles are highly infectious and very often deadly. Each day hundreds of children become victims of this disease. The survivors often suffer consequences for their whole life, like blindness or brain damages. This, even though protecting the children would be so easy.

Measles are extremely infectious and spread especially fast when many people live densely together, as in refugee camps. Especially with weakened children the disease often ends deadly or leads to lasting physical or mental damages. Measles are one of the main causes for blindness among children and often become critical when no medical help is available. This, even though measles vaccination offers quick, reliable, and cheap protection. UNICEF conducts major vaccination campaigns, especially after natural disasters and in other emergency situations, to prevent the spreading of the disease. With a measles you do not only protect the children, but you also reduce the risk for all who get in contact 
with them.
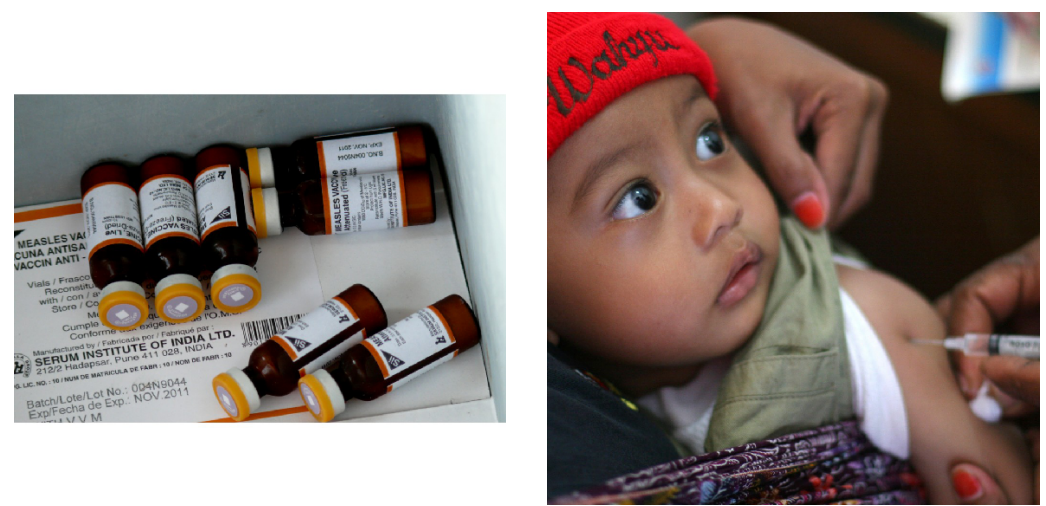

Figure A8: Left: (c) UNICEF/ NYHQ06-1800/ Josh Estey; Right: (c) UNICEF / NYHQ2010-1454/ Christine Nesbitt. 


\subsection{Slides Presented in Treatment DA_PHYSICIAN}

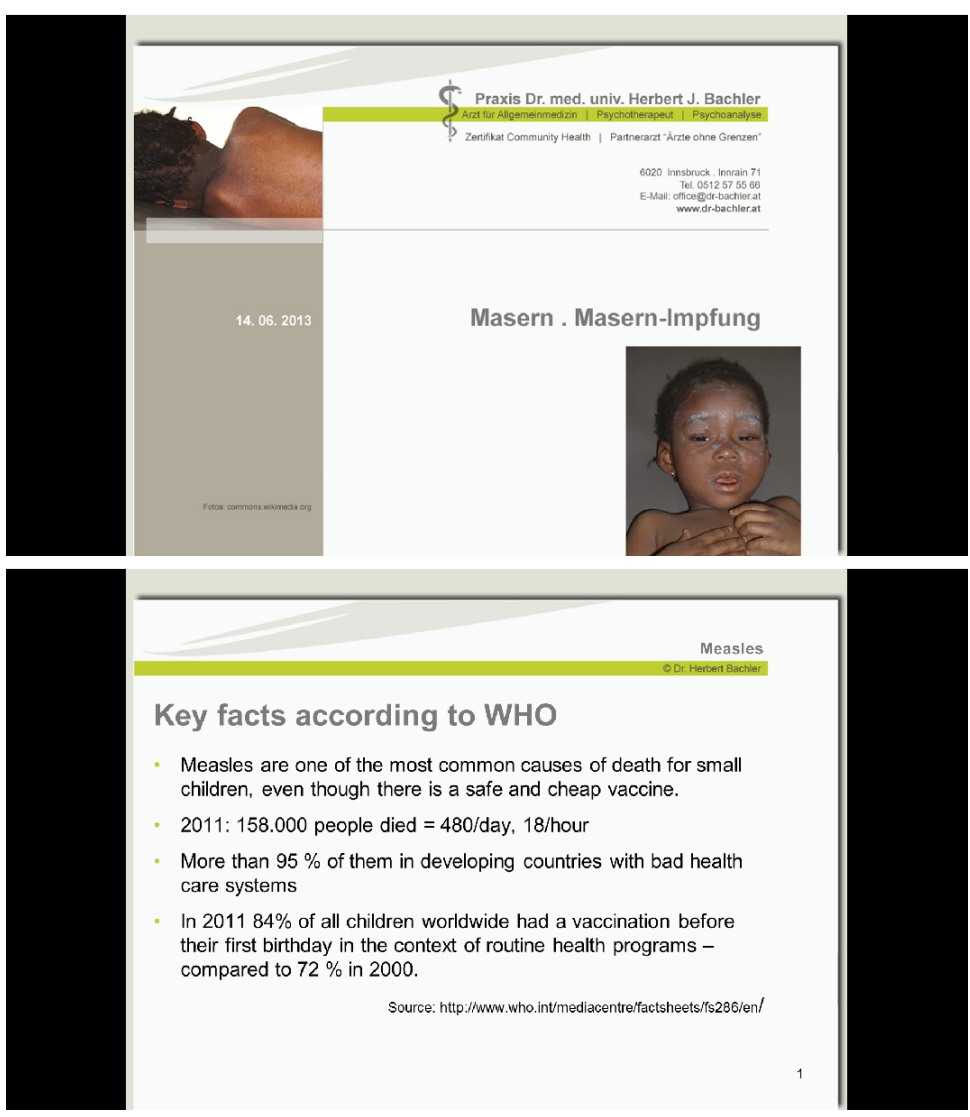

Figure A9: First two slides shown before trading by the physician in treatment DA_PHYSICIAN (translated from German). 

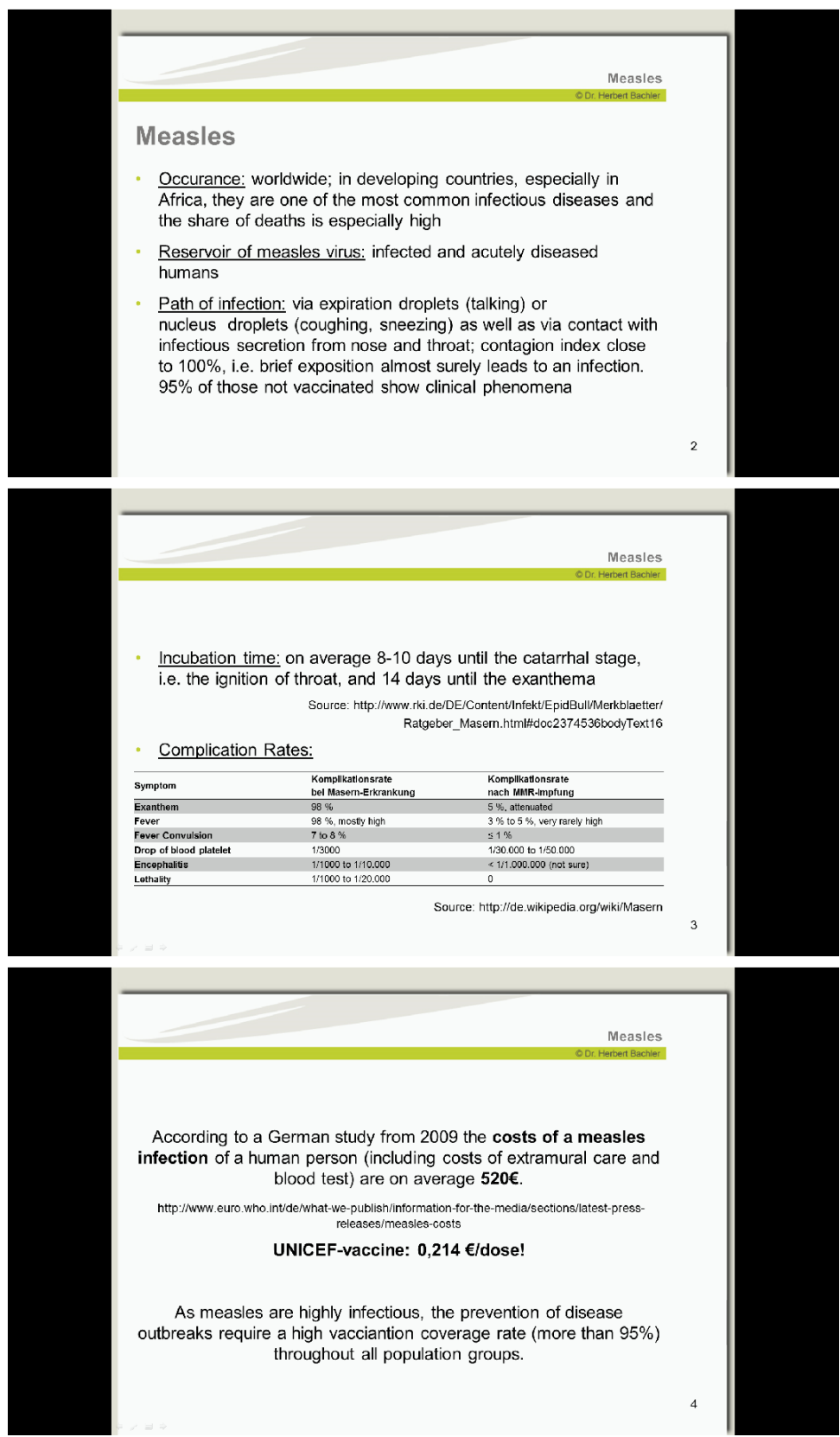

Figure A10: Slides 2 to 4 shown before trading by the physician in treatment DA_PHYSICIAN (translated from German). 


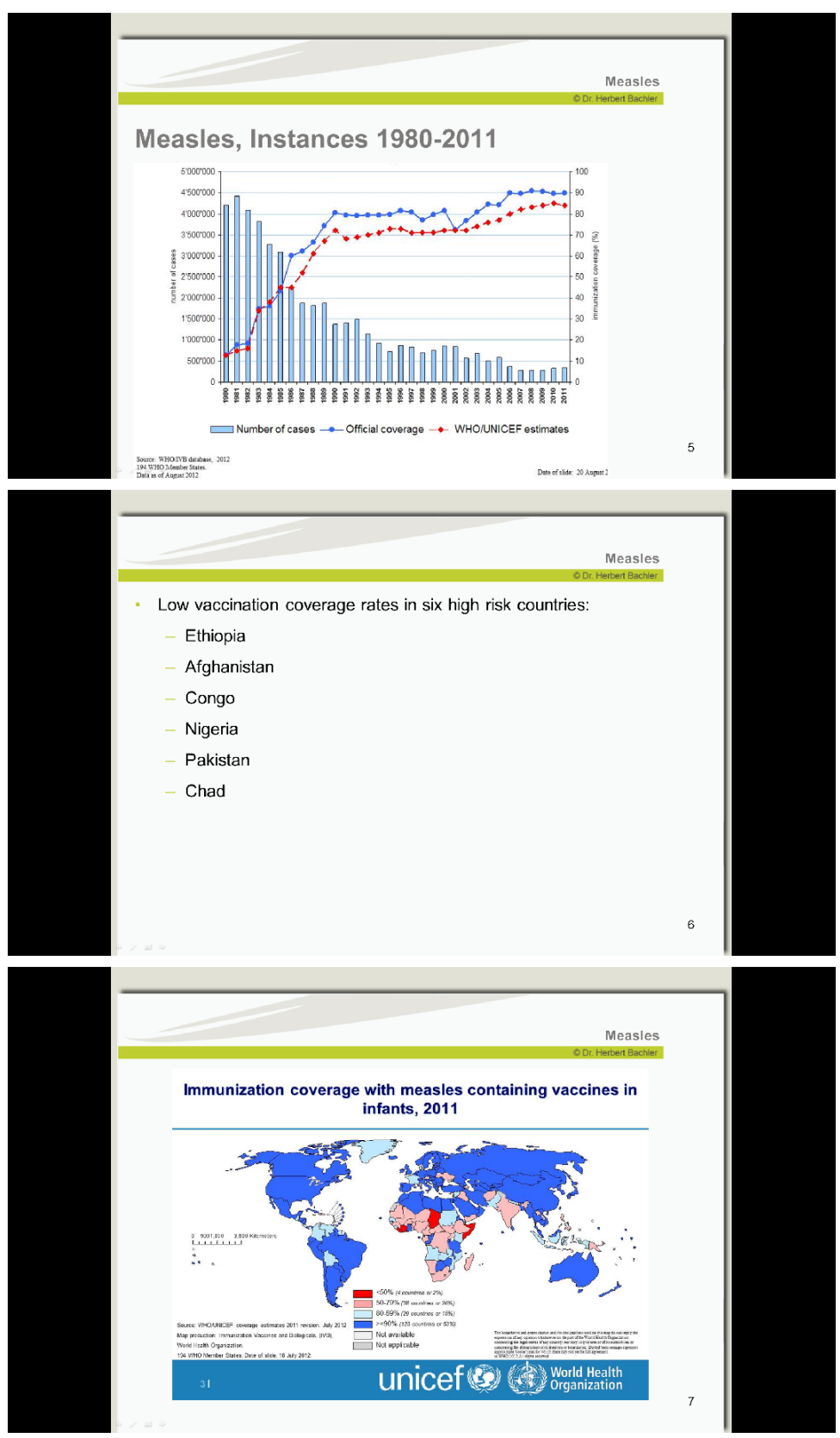

Figure A11: Slides 5 to 7 shown before trading by the physician in treatment DA_PHYSICIAN (translated from German). 


\subsection{Script of the Physician in Treatment DA_PHYSICIAN}

Cover Slide:

Good Day to you all. My name is Dr. Herbert Bachler, I am a general practitioner and family physician in Innsbruck and partner physician of Doctors Without Borders. I will briefly present to you some basic facts on measles and measles vaccine. On the pictures on the first slide you can see the most obvious symptoms of measles, the exanthema. I will tell you more about the symptoms later on.

Slide 1:

Measles are one of the most common causes of death of small children, even though there is a safe and cheap vaccine. In 2011158.000 people died of measles, mostly children under the age of 5 . Almost all of them, more than 95\%, died in developing countries.

The aim is to reach a worldwide vaccination coverage rate of $95 \%$. Although in 2011 this aim was not reached, about $84 \%$ of children worldwide had a vaccination before their first birthday. This is an improvement from $72 \%$ coverage in 2000.

Slide 2:

Measles can be found in the whole world. In developing countries, especially in Africa, measles are one of the ten most common infectious diseases and the death toll is especially high.

The virus has its reservoir in infected and acutely diseased humans. One can get infected via expiration droplets (talking) or nucleus droplets (coughing, sneezing) as well as via contact with infectious secretion from nose and throat. The virus has a contagion index close to $100 \%$, i.e., brief exposition leads almost surely to an infection. $95 \%$ of those not vaccinated show clinical phenomena.

Slide 3:

Incubation time is on average 8-10 days until the catarrhal stage, i.e., the ignition of throat, and 14 days until the exanthema as shown on the first slide.

Here you can see complication rates of not vaccinated versus vaccinated people. You can see that the exanthema decreases from $98 \%$ to $5 \%$, fever from $98 \%$ to 
around $5 \%$ and convulsion from $7 \%$ to below $1 \%$. More important, however, are encephalitis, i.e., inflammation of the brain, and lethality: Both decrease massively, the first from between one out of 1.000 and one out of 10.000 to less than one out of 1.000.000; the latter from between 1 out of 1.000 and one out of 20.000 to 0 .

Slide 4:

A German study calculated the costs of an infection of a human person of around 520 Euro. The UNICEF vaccine, in contrast, costs only 0,214 Euro for one dose. As mentioned before, measles are highly infectious. Preventing the outbreak of the disease, therefore, calls for a high vaccination coverage rate of around 95\% throughout all population groups.

Slide 5:

In this graph you can see the connection between vaccine coverage and diseases. Vaccination increases substantially and the number of diseases has declined. However, developing countries, especially in Africa, still show low vaccination coverage rates and a high amount of diseases which explains the still high death tolls mentioned in the first slide.

Slide 6:

There are six high risk countries with regards to vaccination coverage rates: Ethiopia, Afghanistan, Congo, Nigeria, Pakistan, and Chad. Obviously, most of them are in Africa.

Slide 7:

On the last slide you can see that vaccination coverage is still low in many African and some other developing countries.

Thank you very much for listening and your interest in the topic. 